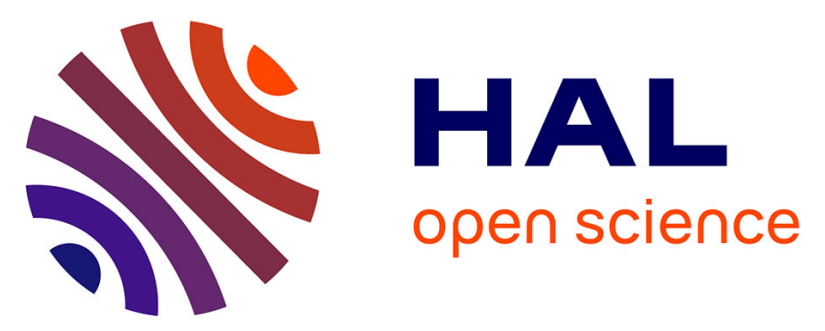

\title{
New insights into the genetic basis of premature ovarian insufficiency: Novel causative variants and candidate genes revealed by genomic sequencing
}

Sylvie Jaillard, K.W. Bell, Linda Akloul, K Walton, Kenneth Mcelreavy, W.A. Stocker, M. Beaumont, C Harrisson, Tiina Jääskeläinen, J.J. Palvimo, et al.

\section{To cite this version:}

Sylvie Jaillard, K.W. Bell, Linda Akloul, K Walton, Kenneth Mcelreavy, et al.. New insights into the genetic basis of premature ovarian insufficiency: Novel causative variants and candidate genes revealed by genomic sequencing. Maturitas, 2020, 141, pp.9-19. 10.1016/j.maturitas.2020.06.004 . hal-02931925

\section{HAL Id: hal-02931925 \\ https://hal.science/hal-02931925}

Submitted on 10 Sep 2020

HAL is a multi-disciplinary open access archive for the deposit and dissemination of scientific research documents, whether they are published or not. The documents may come from teaching and research institutions in France or abroad, or from public or private research centers.
L'archive ouverte pluridisciplinaire HAL, est destinée au dépôt et à la diffusion de documents scientifiques de niveau recherche, publiés ou non, émanant des établissements d'enseignement et de recherche français ou étrangers, des laboratoires publics ou privés. 


\section{New insights into the genetic basis of premature ovarian insufficiency: novel causative variants and candidate genes revealed by genomic sequencing}

\section{Running title: New insights into the genetic basis of POI}

Sylvie Jaillard ${ }^{1,2,3}$, Katrina Bell ${ }^{3}$, Linda Akloul ${ }^{4}$, Kelly Walton ${ }^{5}$, Kenneth McElreavy ${ }^{6}$, William A. Stocker ${ }^{5,7}$, Marion Beaumont ${ }^{2}$, Craig Harrisson ${ }^{5}$, Tiina Jääskeläinen ${ }^{8}$, Jorma J. Palvimo ${ }^{8}$, Gorjana Robevska ${ }^{3}$, Erika Launay $^{2}$, Anne-Pascale Satié ${ }^{1}$, Nurin Listyasari ${ }^{9}$, Claude Bendavid ${ }^{10,11}$, Rajini Sreenivasan ${ }^{3}$, Solène Duros ${ }^{12}$, Jocelyn van den Bergen ${ }^{3}$, Catherine Henry ${ }^{2}$, Mathilde Domin-Bernhard ${ }^{12}$, Laurence Cornevin ${ }^{2}$, Nathalie Dejucq-Rainsford ${ }^{1}$, Marc-Antoine Belaud-Rotureau ${ }^{1,2,13}$, Sylvie Odent ${ }^{4,14}$, Katie L Ayers ${ }^{3,15}$, Célia Ravel ${ }^{1,13}$, Elena J Tucker ${ }^{3,15^{*}}$, Andrew H Sinclair ${ }^{3,15^{*}}$

1- Univ Rennes, CHU Rennes, INSERM, EHESP, IRSET (Institut de recherche en santé, environnement et travail) - UMR_S 1085, F-35000 Rennes, France

2- CHU Rennes, Service de Cytogénétique et Biologie Cellulaire, F-35033 Rennes, France

3- Murdoch Children's Research Institute, Royal Children's Hospital, Melbourne, VIC Australia, 3052

4- CHU Rennes, Service de Génétique Clinique, CLAD Ouest, F-35033 Rennes, France

5- Department of Physiology, Monash Biomedicine Discovery Institute, Monash University, VIC Australia, 3800

6- Institut Pasteur, CNRS - UMR_3738, Paris, France

7- Department of Chemistry and Biotechnology, Swinburne University of Technology, Hawthorn, VIC Australia, 3122

8- Institute of Biomedicine, University of Eastern Finland, Kuopio, FI-70211 Kuopio, Finland

9- Doctoral Program of Medical and Health Sciences, Faculty of Medicine Diponegoro University, Semarang, Indonesia

10- INRAE, INSERM, Univ Rennes, Institut NuMeCan, Rennes, Saint-Gilles, France

11- Laboratoire de Biochimie et Toxicologie; CHU Rennes, Univ Rennes, Rennes, France

12- CHU Rennes, Département de Gynécologie Obstétrique et Reproduction Humaine, F-35033 Rennes, France

13- CHU Rennes, Service de Biologie de la Reproduction-CECOS, F-35033 Rennes, France 
14- Univ Rennes, CNRS UMR 6290 Institut de Génétique et Développement, F-35000 Rennes, France 15- Department of Paediatrics, University of Melbourne, Melbourne, VIC Australia, 3052

*Co-senior authors of this study

Corresponding authors: Sylvie Jaillard, sylvie.jaillard@chu-rennes.fr; Elena J Tucker, elena.tucker@mcri.edu.au

\section{Highlights}

- Our study has provided new insights or strengthened recent claims about the etiology of premature ovarian insufficiency.

- Genomic sequencing of patients with premature ovarian insufficiency or diminished ovarian reserve reveals novel causative variants in STAG3, GDF9, FANCM, and FSHR, and new candidate genes, NRIP1, XPO1, and MACF1.

- We validate that GDF9 and FANCM are responsible for autosomal recessive premature ovarian insufficiency.

- The inability to diagnose some patients is probably the result of the genetic heterogeneity of premature ovarian insufficiency, incomplete understanding of its genetics, and sequencing of singleton DNA.

\footnotetext{
Abstract

Ovarian deficiency, including premature ovarian insufficiency (POI) and diminished ovarian reserve (DOR), represents one of the main causes of female infertility. POI is a genetically heterogeneous condition but current understanding of its genetic basis is far from complete, with the cause remaining unknown in the majority of patients. The genes that regulate DOR have been reported but the genetic basis of DOR has not been explored in depth. Both conditions are likely to lie along a continuum of degrees of decrease in ovarian reserve. We performed genomic analysis via whole exome sequencing
} 
(WES) followed by in silico analyses and functional experiments to investigate the genetic cause of ovarian deficiency in ten affected women. We achieved diagnoses for three of them, including the identification of novel variants in STAG3, GDF9, and FANCM. We identified potentially causative FSHR variants in another patient. This is the second report of biallelic GDF9 and FANCM variants, and, combined with functional support, validates these genes as bone fide autosomal recessive "POI genes". We also identified new candidate genes, NRIP1, XPO1, and MACF1. These genes have been linked to ovarian function in mouse, pig, and zebrafish respectively, but never in humans. In the case of NRIP1, we provide functional support for the deleterious nature of the variant via SUMOylation and luciferase/ $\beta$ galactosidase reporter assays. Our study provides multiple insights into the genetic basis of POI/DOR. We have further elucidated the involvement of GDF9, FANCM, STAG3 and FSHR in POI pathogenesis, and propose new candidate genes, NRIP1, XPO1, and MACF1, which should be the focus of future studies.

\section{Keywords}

Premature ovarian insufficiency, Female infertility, Genomics

\section{Introduction}

Women are born with their future oocyte supply, which is established during development and reaches its maximum size of $\sim 5$ million germ cells around 20 weeks of gestation. After this peak, there is a steady atresia of oocytes with 1-2 million by birth, further depleted to about half a million by menarche [1,2]. After menarche, women lose an average of 1000 oocytes per month, one of which completes maturation and is ovulated as part of the menstrual cycle [3]. The number of oocytes within each woman, corresponding to the ovarian reserve, is variable [4]. The cyclic oocyte maturation and loss of ovarian reserve occurs until menopause at an average age of 51 in the western world.

Ovarian deficiency, including premature ovarian insufficiency (POI) and diminished ovarian reserve (DOR), is one of the main causes of female infertility. A DOR is mostly the consequence of age but is considered abnormal if it occurs before the age of 40 (10\% of women) [4]. In contrast, premature ovarian insufficiency (POI) is characterized by perturbation or cessation of the menstrual cycle along with elevated gonadotropins before the age of 40, affecting as many as 1 in 100 women. There is no evidence that DOR is a precursor of POI and women under 40 can have a DOR without POI. Nevertheless, these conditions are likely manifestations along a continuum of ovarian deficiency with different severity of decrease in ovarian reserve. POI can be devastating for affected women who face 
infertility, as well as an increased risk of co-morbidities such as cardiovascular disease, mental health problems, osteoporosis and earlier mortality [5,6]. The cause of POI is manifold. It can be secondary to medical interventions or can occur as part of autoimmune conditions, metabolic conditions or genetic syndromes. There is a tendency for affected individuals to have affected family members, indicating the role of inheritance in the condition $[7,8]$. The genetic basis of $\mathrm{POI}$ is further demonstrated by the discovery of causative variants in over 50 different genes [6]. These genes have diverse roles including metabolism, folliculogenesis, gonadogenesis, oogenesis, DNA damage repair, apoptosis, hormone signaling, autoimmunity and more. Current understanding of the genetic basis of POI, however, is far from complete, with the cause remaining unknown in the majority of patients, particularly those with sporadic and isolated POI. Key regulating genes of DOR have also been reported [9] but the genetic basis of DOR has not been explored in depth. Importantly, overlapping genetic background has been reported for POI and DOR [10] providing rationale for testing both conditions using similar methods.

In this study, we have used whole-exome sequencing (WES) followed by thorough variant curation and functional validation to investigate the genetic cause of POI and DOR in a small cohort of 10 patients. All patients had isolated POI or DOR with no related medical history, and were initially analysed as singletons. We were able to provide likely genetic diagnoses to three patients who harboured novel variants in the known POI-related genes STAG3, GDF9, and FANCM. Another patient had variants of uncertain significance with high clinical relevance in FSHR. We also propose the potential involvement of variants in NRIP1, XPO1, and MACF1, three genes known to have a role in ovarian biology but never before associated with human POI.

\section{Material and methods}

\subsection{Ethical adherence and participants}

Written informed consent was obtained from all participants. All procedures were in accordance with the ethical standards of the Ethics Committee of Rennes University Hospital and the French law (favourable opinion from the CCTIRS - Comité Consultatif sur le Traitement de I'Information en matière de Recherche dans le domaine de la Santé - for the study).

Patients were recruited for the study after clinical consultation. They were all of Caucasian origin. All patients underwent cytogenetic analysis demonstrating normal 46,XX karyotype, and normal microarray (Agilent 180K), were negative for FMR1 premutation and auto-antibodies (when available). Parental DNA was not available for WES but was retrospectively obtained for three patients.

\subsection{Methods}




\subsubsection{General molecular techniques}

Genomic DNA was extracted from EDTA-blood samples with the NucleoSpin ${ }^{\circledast}$ Blood XL kit (MachereyNagel, Düren, Germany) and were assessed by NanoDrop ${ }^{\mathrm{TM}} 1000$ spectrophotometer and Qubit dsDNA BR Assay (Thermo Fisher Scientific, Waltham, MA, USA).

Selected SNVs were validated by Sanger sequencing using BigDye v3.1 Terminators (Applied Biosystems, Foster City, CA, USA) and ABI 3130X. Primer sequences are available on request.

Phasing was performed by cloning in the pGEM-T Easy Vector (Promega Corporation, Madison, WI, USA) (detailed method in Supplementary File 1).

Blood RNA was extracted with a Nucleospin RNA blood kit (Macherey Nagel, Düren, Germany) according to the manufacturer's instructions. An additional DNase treatment was performed using the RQ1 RNaseFree DNase kit (Promega Corporation, Madison, WI, USA). Reverse transcription (RT) was performed on DNAse-treated RNA using the GoScriptTM Reverse Transcription System (Promega Corporation, Madison, WI, USA) as per manufacturer's protocols. To verify lack of residual genomic DNA in downstream reactions, control reactions were included without reverse transcriptase (-RT).

\subsubsection{Whole-exome sequencing (WES)}

DNA underwent WES at the Australian Genome Research Facility (AGRF). Exome capture was performed with Agilent SureSelect Human All Exon V6 (Agilent) and sequencing was performed on the NovaSeq 6000 (Illumina). All WES data were processed using Cpipe [11] and deposited into SeqR for analysis (https://seqr.broadinstitute.org/).

We performed two phases of analysis - the first focused on gene priority and the second focused on variant priority, as previously described [6]. MAF and tolerance of genes to missense and/or loss-offunction (LoF) variation were assessed in the public database gnomAD (https://gnomad.broadinstitute.org/). Variant pathogenicity was predicted in silico using Mutation Taster (http://www.mutationtaster.org/), Polyphen-2 (http://genetics.bwh.harvard.edu/pph2/), SIFT/Provean (http://provean.jcvi.org/), DANN (Deleterious Annotation of genetic variants using Neural Networks) score [12] and CADD (Combined Annotation-Dependent Depletion) score (https://cadd.gs.washington.edu/snv). The conservation of affected nucleotides and residues in mammals, birds, reptiles and fish was also taken into account with GERP (Genomic Evolutionary Rate Profiling) score and Multiz Alignments of 100 vertebrates (UCSC Genome Browser https://genome.ucsc.edu/). Variants were curated using the American College of Medical Genetics and Genomics (ACMG) criteria, adapted for use by the Victorian Clinical Genetics Service [13]. The effects of 
the missense mutations identified were assessed using the HOPE database [14] for the clinically relevant variants.

\subsubsection{Analysis of sensitivity to chromosomal breakage}

$72 \mathrm{~h}$ blood culture was performed with phytohemagglutinine, without treatment and after exposure to Mitomycin C (10 $10^{-7} \mathrm{M}, 30 \mathrm{ng} / \mathrm{ml}$ final concentration) (Sigma-Alrich, Saint-Louis, MI, USA) added after $24 \mathrm{~h}$ of culture. Metaphase spreads were colored by Giemsa. Baseline and DNA-induced chromosome breakage and rearrangements were scored on 50 metaphases in the patient and in a control. Two assays were performed on two different samples obtained four months apart.

\subsubsection{Enzyme-linked immunosorbent assays (GDF9 gene)}

ELISA sandwich assays were performed on serum of the patient using two GDF-9 ELISA kits (AnshLabs, Webster, TX, USA and LifeSpan BioSciences, Inc., Seattle, WA, USA) according to the manufacturers' protocols. For the AnshLabs kit, the antibodies were raised from full-length GDF9 protein, and detect the pro-region (aa 25-319) and mature region (aa 320-454). For the LifeSpan BioSciences kit, capture and detection antibodies are rabbit polyclonal antibodies affinity purified, standard and immunogen are a recombinant protein produced in E.coli encoding aa 320-454, and the epitopes recognized by the polyclonal antibodies have not been mapped. Fluorescence was measured using the Varioskan Flash (Thermo Fisher Scientific, Waltham, MA, USA) and iMark ${ }^{\mathrm{TM}}$ Microplate Absorbance Reader (Bio-Rad, Hercules, CA, USA).

\subsubsection{Expression plasmids}

Wild-type human GDF9 and BMP15 expression plasmids containing $\mathrm{N}$-terminal poly-histidine tags have been described previously [15]. Pro374Leu and Leu265* variants were inserted into the WT His-tagged GDF9 plasmid via in vitro site-directed mutagenesis.

Expression plasmid with the NRIP1 variant was created by site-directed mutagenesis of the previously described pSG5-HA-RIP140-WT expression vector [16] to generate pSG5-HA-RIP140-STOP1087MUT.

\subsubsection{Western blot}

Transient transfection of HEK293 cells with GDF9 variants either alone or in combination with BMP15, followed by Western blotting of conditioned media and cell lysates was carried out as described previously [17]. To detect precursor and mature forms of GDF9 in conditioned media and cell lysates, blots were probed with mAb-53/1 (Oxford Brookes University, Oxford, UK, 1:5000), which is targeted to an epitope near the C-terminus of GDF9 [18]. Recombinant human GDF9 mature domain (R\&D Systems, Minneapolis, MN, USA - 8266-G9-010) was used as reference. To detect BMP15 and GDF9 precursors in cell lysates, blots were probed with anti-6X-His (R\&D Systems - MAB050, 1:2000). 
COS1 cells were transfected with pSG5-HA-RIP140-WT or pSG5-HA-RIP140-STOP1087MUT alone or cotransfected with pSG5-His-SUMO-1 or pSG5-SUMO-2 in duplicate. Western blotting was performed using antibodies to detect the following: HA-RIP140: $\alpha$-HA (Bio-Legend, San Diego, CA, USA - 16B12, 1:1500), SUMO1: $\alpha$-GMP-1 (Invitrogen, Carlsbad, CA, USA - 332400, 1:500), SUMO2: $\alpha$-SUMO2/3 (MBL Life Science, Woburn, MA, USA - M114-3, 1:2000), and GAPDH: $\alpha$-GAPDH (Santa Cruz Biotechnology, Inc, Dallas, TX, USA - FL-335, 1:5000). Total wild-type (WT) and mutant NRIP1 protein expression was calculated using GAPDH as loading control. Percentage of SUMOylated NRIP1 relative to total NRIP1 was calculated.

\subsubsection{ER $\alpha$ luciferase/ $\beta$-galactosidase reporter assay}

Twenty-four hours before transfection, COS-1 cells were seeded onto 12 -well plates, and were cotransfected with 200 ng pGL3-ERE3, 20 ng pCMV- $\beta$-gal, 20 ng pSG5-hER $\alpha$ and pSG5-HA-RIP140-WT or pSG5-HA-RIP140-STOP1087MUT using TransIT-LT1 according to the manufacturer's instructions. Media was replaced with $2.5 \%$ charcoal-stripped fetal bovine serum $4 \mathrm{~h}$ before transfection, and vehicle/E2 (100 $\mathrm{nM}$ ) was added $24 \mathrm{~h}$ after transfection. Forty-eight hours after transfection, the cells were harvested and lysed in reporter lysis buffer (Promega Corporation, Madison, WI, USA). The cleared supernatants were used for $\beta$-galactosidase assays as described previously [16]. Total NRIP1 protein concentration was measured using western blot with $\alpha-H A$. The relative LUC activities (i.e. luciferase light units divided by $\beta$-galactosidase values or protein concentration) are represented as the means \pm the standard deviations. The experiments were done in triplicate.

\section{Results}

We analysed the exome of ten patients with isolated POI or DOR. A summary of patient phenotype is shown in Table I and a summary of prioritized variants is provided in supplementary material (Supplementary File 2). Nomenclature validation was performed using Variant Validator https://variantvalidator.org/.

\subsection{Diagnoses in known POI genes}

\subsubsection{Pathogenic homozygous missense STAG3 variant}

In Patient 3, a homozygous variant in STAG3 (OMIM*608489) NM_012447.3:c.962G>A, NP_036579.2:p.(Arg321His) was identified and predicted to be "pathogenic" after variant curation using ACMG-based criteria (1 PS, 1 PM, and 5 PP). This variant is the focus of another study (manuscript under review).

\subsubsection{Likely pathogenic compound heterozygous GDF9 variants}


In Patient 2, we identified two rare heterozygous variants in GDF9 (OMIM*601918). Patient 2 experienced primary amenorrhea and was diagnosed with non-syndromic POI at 18 years-old. Her familial pedigree shows, notably, dizygotic twin siblings (Figure 1a). The variants were validated by Sanger sequencing, and cloning demonstrated they were in trans, confirming compound heterozygosity (Figure 1b). The nonsense NM_005260.5:c.794T>G, NP_005251.1:p.(Leu265Ter) variant falls within the second and last exon of GDF9 and is therefore predicted escape nonsense-mediated decay (NMD), and instead encode a truncated protein. This truncation impacts the C-terminal mature bioactive domain. The second GDF9 variant NM_005260.5:c.1121C>T, NP_005251.1:p.Pro374Leu, is a missense variant that falls within the TGF $\beta$-like domain (Figure 1c). ELISA sandwich assay showed a low level in the serum which was not significantly different from that observed in the control (Supplementary File 3) reflecting the sensitivity limit of the assay. The low level of GDF9 expression in patient's blood precluded further analysis, so we instead investigated the variants in vitro using HIS-tagged expression constructs and transient expression in HEK293 cells. Western blot demonstrated that WT GDF9 could be detected in conditioned media from transfected cells, however, GDF9-P374L (p.Pro374Leu) was almost undetectable and GDF9-L265* (p.Leu265Ter) was completely undetectable, indicating the variants impair the formation of GDF9 and/or its secretion into media (Figure 1d). Recent evidence suggests that in humans GDF9 is activated by forming a heterodimer called 'cumulin' with the related protein BMP15 $[15,19]$. Therefore, we also examined heterodimerisation with BMP15. Interestingly, the GDF9 variants appeared to compromise the expression of BMP15, likely affecting production of BMP15 homodimers and the more active cumulin heterodimer (Figure 1d). Analysis of the precursor and mature GDF9 indicates successful processing of the WT His-tagged GDF9. In contrast, precursor GDF9-P374L is detected but no mature protein is evident suggesting this variant impairs GDF9 dimerisation and/or processing. Both the precursor and mature GDF9-L265* peptide are undetectable suggesting this variant, instead, affects protein formation (Figure 1d). Using ACMG criteria, these compound heterozygous GDF9 variants are classified as "likely pathogenic" (nonsense variant: 4PM, 1PP and missense variant: 3PM, 3PP). This is only the second described case of biallelic GDF9 variants associated with POI [20].

\subsubsection{Pathogenic FANCM variants}

In patient 5, two nonsense variants in FANCM (OMIM*609644) were identified: NM_020937.3:c.3088C>T, NP_065988.1:(p.Arg1030Ter) and NM_020937.3:c.5791C>T, NP_065988.1:(p.Arg1931Ter) (Figure 2a). Patient 5 experienced secondary amenorrhea and nonsyndromic POI was diagnosed at 25-year-old. Both nonsense variants are rare, but present, in gnomAD 
with 0.000003996 (1 het.) and 0.001012 (286 het.) frequency respectively. None of the variants fall within the terminal exon indicating NMD is likely, and suggesting that the patient likely has a lack of FANCM expression. This is in keeping with previously reported patients, sisters with non-syndromic POI harbouring a homozygous LoF allele [21]. Chromosome breakages and rearrangements were higher in our patient than in a control (Figure 2b). The familial history was concordant with a recessive-type condition: while no particular phenotype was noted in the parents, the patient has an older sister diagnosed with non-syndromic POI at 30 years of age. While the c.3088C $>\mathrm{T} / \mathrm{p}$.Arg1030Ter is not reported in ClinVar, the c.5791C>T/p.Arg1931Ter variant has three entries, two of which indicate it as pathogenic. The phenotype of the patients in ClinVar with this variant includes Fanconi anemia (uncertain significance), malignant germ cell tumour of the ovary (pathogenic) and spermatogenic failure (pathogenic). Our curation using ACMG-based criteria indicates these variants are "pathogenic", (each with one very strong criterion (1VS) and 2PS, as well as other supporting criteria) based on predicted LoF, co-occurrence with a second pathogenic variant, the phenotype match with published patients with variants in this gene, functional evidence of chromosomal instability, and the familial history and variant segregation consistent with a recessive-type condition.

\subsubsection{Variants of uncertain significance with high clinical relevance in FSHR}

Patient 4 had two rare moderate-high priority recessive-type variants in a known POI gene, FSHR (OMIM *136435): NM_000145.3:c.236A>C， NP_000136.2:p.(GIn79Pro) and NM_000145.3:c.1771T>C, NP_000136.2:p.(Phe591Leu) (Supplementary File 4). Patient 4 experienced primary amenorrhea with presence of antral follicles, corresponding to a resistant ovary syndrome (ROS: elevated FSH with normal antral follicle count and normal AMH). FSHR belongs to the G protein-coupled receptor family, with an extracellular domain (ECD), a seven helix transmembrane domain (TMD), and an intracellular domain (ICD). The first variant p.(GIn79Pro) falls within a leucine-rich repeat region of the ECD and the second p.(Phe591Leu) falls within the TMD (Supplementary File 4). In silico structural analysis using HOPE showed that both variants can affect protein function, due to their location in domains important for the activity of the protein and for p.(Gln79Pro), disturbance of the interactions existing with residues in another domain. Using ACMG-based variant curation criteria, these variants are classed as "variants of uncertain significance with high clinical relevance" (1PM and 3PP each). If these variants could be phased and proven to be in trans, the variant categorization would meet criteria to be considered "likely pathogenic" (1PM and 4PP) however, parental DNA was not available, nor was patient RNA that would allow phasing by cloning. The presence of high FSH associated with normal AMH and AFC in the patient, consistent with a diagnosis of ROS, is in favor of variants pathogenicity. 


\subsection{Variants of interest in novel POI genes}

Three major candidate genes were noted, each intolerant to LoF variants but harbouring predicted LoF variants in POI patients, and having known roles in ovarian biology. We describe these genes and variants below.

\subsubsection{NRIP1}

A heterozygous nonsense variant in NRIP1 (OMIM*602490) NM_003489.3: c.3259A>T, NP_003480.2: p.(Lys1087Ter) was identified in Patient 9 (Figure 3a). Disruption of this gene in mice leads to impaired oocyte maturation/ovulation [22]. This LoF variant has not been previously reported (MAF=0). NRIP1, encoding a nuclear receptor transcriptional coregulator, is highly intolerant of LoF variation according to gnomAD database with a $\mathrm{pLI}$ of 0.99 and a significantly low observed:expected ratio resulting from only four LoF variants recorded compared to the expected 33. Human NRIP1 contains four transcriptional repression domains and ten interaction motifs (Figure 3b) [23]. The variant is found within the only protein-coding exon of this gene, meaning the transcript likely escapes NMD. We confirmed the stability of variant mRNA by RT-PCR showing retained expression (Figure 3c). The variant lies within the $4^{\text {th }}$ repression domain and the predicted truncated protein lacks Lys ${ }^{1154}$, a residue known to be required for SUMOylation [16]. Disruption to this site impairs the ability of NRIP1 to repress transcription and alters its intranuclear localization in response to SUMO-1 [16]. We investigated whether the patient variant similarly alters NRIP1 function by introducing the variant into an expression vector and comparing the ability of WT and variant NRIP1 to be SUMOylated by SUMO1 and SUMO2. SUMOylation of variant NRIP1 was half as efficient as WT. While $~ 33 \%$ of WT NRIP1 was SUMOylated by SUMO1, only $16 \%$ of variant NRIP1 was. Similarly, SUMO2 SUMOylated $\sim 50 \%$ of WT NRIP1 but only $\sim 23 \%$ of mutant NRIP1 (Figure 3d). This demonstrates a clear in vitro functional impairment due to the NRIP1 variant carried by the patient. We also analysed the ability of variant NRIP1 to act as a co-repressor of ER- $\alpha$. We used an $E R \alpha$ luciferase/ $\beta$-galactosidase reporter assay. The addition of estradiol (E2) increases the relative expression from this reporter 14 fold (from 14 to $>200$ luc/Bgal). This E2-induced ER $\alpha$ reporter expression is repressed by the addition of WT NRIP1, and the degree of repression increases as the level of NRIP1 protein increases. The ability of variant NRIP1 to repress ER $\alpha$ reporter expression in response to E2 is significantly hampered at all expression levels (Figure 3e). Again, this demonstrates that the variant has a clear effect on the in vitro function of NRIP1. We have demonstrated an impaired function of mutant NRIP1 and humans are intolerant to LoF variation in this gene. We predict that the gene causes POI due to haploinsufficiency, however, it cannot be known whether the degree of loss of 
function is sufficient to induce POI in humans. Further functional work and/or additional human cases with variants in this gene will help to clarify this.

\subsubsection{XPO1}

Patient 9 also has a frameshift variant in XPO1 (OMIM*602559) NM_003400.3: c.1693_1694delGT, NP_003391.1: p.(Val565SerfsTer2) which has not been previously reported (MAF=0). XPO1, a gene also intolerant to LoF, encodes a karyopherin, and is expressed in mouse developing ovary and mammalian oocytes [24,25]. XPO1 is involved in primordial follicle activation [24] and has a role in germinal vesicle maintenance and meiotic resumption of oocytes [25]. XPO1 inhibition in porcine oocytes leads to impaired germinal vesicle breakdown due to the lack of nuclear export of maturation-regulating factors [25], further strengthening the link between this gene and ovarian function. Its contribution to the phenotype, alone or in association with NRIP1, cannot be ruled out and further functional studies are required to prove its involvement in $\mathrm{POI}$ pathogenesis.

\subsubsection{MACF1}

One stand-out candidate in Patient 6 was a frameshift variant in MACF1 (OMIM*608271), NM_012090.5:c.5539dupA, NP_036222.3:p.(Ser1847LysfsTer44). This gene has been implicated in ovarian function in mouse, zebrafish, and fly [26-28]. It is highly intolerant of LoF variation, with only 18 LoF variants detected in gnomAD in contrast to the 318 expected. The variant lies within the $37^{\text {th }}$ exon of this large 91-exon gene, and is therefore predicted to induce NMD. Patient RNA was not available for confirmation.

\subsection{Variants of uncertain significance (VUS)}

The afore-mentioned variants constitute those considered most likely involved in the POI/DOR pathogenesis. There are, however, many other variants that may be involved either in isolation or synergistically. A summary of VUS is presented and discussed in Supplementary Files 2 and 5. We do not provide an exhaustive discussion of VUS and the discussed variants require further functional validation. The small number of patients studied and the genetic heterogeneity of POI meant we did not identify a common genetic defect in these patients. Until additional patients with the same phenotype are identified with variants in the same genes, the involvement of these genes is likely to remain uncertain.

\section{Discussion}

In this study, we have used WES to investigate the genetic cause of POI in a small cohort of 10 French women. The first analysis focused on $492 \mathrm{POI}$ diagnostic or candidate genes selected from public databases and from literature data. We were successful in identifying the likely genetic cause for three 
patients, with novel variants in STAG3, GDF9, and FANCM. One additional patient had variants of uncertain significance with high clinical relevance in a validated POI gene, FSHR. These novel variants provide new insights into the genetics of POI.

Our study is the second report of biallelic GDF9 variants in a patient with POI [20]. GDF9 is a member of the TGF- $\beta$ superfamily, is critical for mammalian ovarian folliculogenesis, and is a key factor for granulosa cell proliferation and differentiation. GDF9 is strongly expressed in oocytes at all stages of developing follicles except primordial follicles [29]. Heterozygous variants have been associated with POI, DOR, polycystic ovarian syndrome and mothers of dizygotic twins (DZT) suggesting the involvement of GDF9 in multiple aspects of ovarian function [29-31]. Reduced expression and/or altered activity of the protein have been proven for most of these variants, with a particularly abrogated expression of GDF9 harbouring p.Pro374Leu. This variant was significantly more frequent in mothers of DZT suggesting that an enhanced ovulation rate may be associated with reduced GDF9 signaling. This is true for a naturally occurring GDF9 variant in sheep, which causes increased fecundity when heterozygous but sterility when homozygous [32]. Interestingly, the mother of patient 7 also had spontaneous DZT. Parental DNA was not available for sequencing, but it is possible that the mother harbours the p.Pro374Leu variant, contributing to her twin pregnancy. Despite the described association of heterozygous variants with ovarian pathology, heterozygous GDF9 variants have also been observed in healthy women, like the mother and unaffected sister of the reported patient by Franca et al. [20], casting doubt on haploinsufficiency of GDF9 causing POI. The heterozygous GDF9 variants may be associated with a less severe phenotype (i.e. POI with secondary amenorrhea) whereas biallelic variants may lead to a more severe phenotype, such as primary amenorrhea, as in patient 7 . The contribution to a more or less severe phenotype in an allele-dependent manner has recently been suggested for other genes [33].

FANCM is a tumor suppressive DNA translocase that controls the outcome of homologous recombination and is involved in the DNA replication process [34]. Fancm ${ }^{-/}$female mice have depletion of primary follicles, impaired folliculogenesis, and abnormal meiotic recombination [21]. Bi-allelic LoF variants have recently been shown to cause non-syndromic POI in women [21], as well as spermatogenic failure in men $[35,36]$ consistent with its role in homologous recombination in both sexes. Only one variant has been described in association with idiopathic POI, limiting the ability to class this gene as diagnostic for curation purposes. We present the second report of FANCM variants associated with POI and chromosomal instability, consolidating variants in this gene as a bone fide cause. Pathogenic variants are considered as predisposition factors for early onset breast cancer, with monoallelic 
nonsense variants in $2.1 \%$ of those affected [37]. Heterozygous variants have also been implicated in the development of other cancers such as ovarian cancer [34], and one of the variants carried by Patient 5, in particular, is reported in ClinVar in association with an ovarian germ cell tumour. No history of breast or ovarian cancer was detected in our family; however, the known link between FANCM and cancer, along with the evidence of chromosomal instability in our patient, indicates that she may benefit from cancer surveillance.

FSHR belongs to the G protein-coupled receptor family, with an extracellular domain, a transmembrane domain, and an intracellular domain. More than 20 inactivating variants have been reported to date, located in the three domains of the protein $[38,39]$. This gene is one of the few POI genes for which a genotype:phenotype correlation has been suggested [6]. Completely inactivating variants are supposed to cause POI in the context of primary amenorrhea and hypoplastic ovaries, with a block in follicular growth from the primary stage $[39,40]$, whereas partially functional variants have been described in association with a milder phenotype of POI in the context of secondary amenorrhea and normal-sized ovaries, with normal initial follicular development [41]. This is in accordance with the importance of gonadotropins in the late stages of follicullogenesis. Recently, the absence of correlation between in vitro FSHR function (complete or partial LoF) and whether ovarian follicles are present cast doubt upon this evidence, highlighting the difficulty to assess in vivo ovarian function by in vitro studies, and the importance of genetic background [39]. Validated FSHR variants have been described in association with resistant ovary syndrome (ROS), which manifests as high FSH but normal ovarian reserve as determined by AMH and AFC $[38,39]$. The patient described here with two novel FSHR variants also presented with this phenotype. Women with ROS should undoubtedly consider undergoing variant screening for FSHR [39].

In addition to the variants in validated POI diagnostic genes and the novel insights these have provided, many variants in interesting candidate genes were identified. We propose three new candidate genes involved in POI pathogenesis, NRIP1, XPO1, and MACF1.

NRIP1 is a widely-expressed hormone-responsive repressor of nuclear receptors of many different nuclear receptors [42-45]. It directly interacts with retinoic acid receptors to suppress retinoic acidmediated signaling [46], which has a known role in oogenesis [47]. Female mice lacking Nrip1 (RIPKO mice) are infertile due to a failure to release mature oocytes at ovulation [22]. Importantly, heterozygous RIPKO mice also have impaired ovulation suggesting that an absolute level of Nrip1 is essential for ovarian function [22]. Haploinsufficiency of NRIP1 in humans has been associated with congenital anomalies of the kidney and urinary tract in a large family pedigree [48] although ovarian 
function was not described. No kidney or urinary tract malformation was noted in the patient of this study. We validated that the variant led to functional impairment in vitro. The relevant mouse phenotype, the intolerance of this gene to nonsense variation combined with the predicted severity of the variant and its proven functional impact, provide strong evidence for NRIP1 as a new candidate gene underpinning human $\mathrm{POI}$ pathogenesis.

$X P O 1$, also called CMR1, is a major nuclear export receptor belonging to the karyopherin $\beta$ family, with an exportin function. XPO1 is predicted to recognize about 300 cargos, all harbouring nuclear export signals in their polypeptide chains (leucine-rich-NES) [49]. Misregulation of cargo proteins and misexpression of XPO1 have been observed in malignancies [49]. The role for karyopherin in the female germline have been demonstrated thought studies in mouse oocytes showing Xpo1 expression in embryonic and adult ovary, and its involvement in regulation of primordial follicle activation [24]. Karyopherin also regulate meiotic entry through appropriate relocation of important cell cycle regulators, and in keeping with this, a key cargo proposed for XPO1 is STRA8, an essential meiotic entry factor [24]. These exportin are also involved in oocyte growth regulation and XPO1 regulates germinal vesicle maintenance and meiotic resumption of oocytes in pig [25].

MACF1 is a member of the spectraplakin family of proteins, and is an enormous cytoskeletal protein that interacts with microtubules, actin filaments and intermediate filaments [50]. Macf1 positively regulates the Wnt- $\beta$ catenin pathway [51] whose disruption causes a POI-like phenotype in mice [26]. Furthermore, deletion of the MACF1 orthologue in Zebrafish leads to aberrant oocyte polarization and subsequent infertility [27]. LoF mutations as well as dominant-negative mutations of the Drosophila equivalent of MACF1, Short stop (Shot), lead to defects in oogenesis [28]. Other microtubule-binding proteins have been implicated in POI in both humans and other species [52,53]. The roles of microtubule-binding proteins for oocyte function include signal transduction, regulation of the meiotic spindle assembly as well as oocyte polarization. In humans, SNPs affecting the MACF1 locus have been found to associate with schizophrenia [54], Parkinson's disease [55], and cancers [56]. Pathogenic variants in MACF1 can cause neurological diseases, spectraplakinopathy type 1 [57] and lissencephaly [58], however ovarian dysfunction is not described in these patients. The different clinical presentation of the patient described here may be the result of a different consequence of the variant. Indeed, lissencephaly is specifically caused by disruption to the GAR domain, in contrast to the predicted LoF variant identified in our patient. MACF1, does indeed, have multiple isoforms and alternative splicing, and the variant described here may have a pronounced effect on an isoform with a predominant role in oocytes, analogous to TP63 variants that can cause isolated POI or multiorgan syndromes depending on 
the nature of the variant and the isoforms it impacts [53]. The relevant role of MACF1 in ovarian biology, the phenotype of model organisms with Macf1 disruption, the intolerance of this gene to LoF variant and the severe nature of the detected variant indicate that this gene is a strong POI candidate. Further work is required to establish the role of this gene, and the variant, in human oocyte function.

WES has proven efficacy in POI gene discovery, and has been responsible for the discovery of the majority of human POI genes identified in recent years. WES is also adapted for the diagnosis of genetic diseases with a heterogeneous basis such as POI for which oligogenic origin is often suspected [59]. The overall genetic diagnosis in 3 of 10 patients indicates relative diagnostic success [33,60]. As for previous studies, re-analysis of data in the light of new published literature and using modified analysis protocols is likely to yield additional diagnoses within the data [61,62]. The inability to diagnose some patients is probably the result of 1 ) the genetic heterogeneity of POI, thereby limiting the ability to confirm gene involvement by identifying multiple unrelated individuals affected by variants in the same gene; 2) incomplete understanding of POI genetics, leading to failure in identifying POI candidates given we prioritized moderate to high impact variants in POI candidate or diagnostic genes, but only high impact variants in the remaining genes and; 3 ) sequencing of singleton DNA. Without parental DNA to validate compound heterozygosity or to discount maternal inheritance of potential dominant-acting variants, we are limited in our ability to draw conclusions. The FSHR variants in Patient 8 , for example, could be considered "likely pathogenic" using ACMG criteria if we had parental DNA to demonstrate they are truly compound heterozygous.

In summary, our analysis of women with POI or DOR using WES and stringent ACMG-based criteria to define pathogenicity identified novel likely pathogenic variants in STAG3, GDF9, and FANCM, and variants of uncertain significance with high clinical relevance in FSHR. This has provided new insights or strengthened recent claims about the etiology of POI. Being only the second report of biallelic GDF9 and FANCM variants in POI patients, our study validates that these genes are responsible for autosomal recessive POI. We also identify variants of interest in genes never before associated with human POI, in particular NRIP1, XPO1, and MACF1. We provide functional evidence of impaired NRIP1 activity of the variant protein. This study provides new insights into the genetic basis of POI and multiple avenues for further investigations. 


\section{Contributors}

Sylvie Jaillard conceived and designed the study, acquired the data, analyzed and interpreted the data, and wrote the manuscript.

Katrina Bell analyzed and interpreted the data.

Linda Akloul was involved in patient care and evaluation.

Kelly Walton was involved in the functional studies.

Kenneth McElreavy analyzed and interpreted the data.

William A. Stocker was involved in the functional studies.

Marion Beaumont managed the cytogenetic analysis.

Craig Harrisson was involved in the functional studies.

Tiina Jääskeläinen was involved in thhe functional studies.

Jorma J. Palvimo was involved in the functional studies.

Gorjana Robevska supplied technical support.

Erika Launay managed the cytogenetic analysis.

Anne-Pascale Satié supplied technical support.

Nurin Listyasari supplied technical support.

Claude Bendavid supplied technical support.

Rajini Sreenivasan analyzed and interpreted the data.

Solène Duros was involved in patient care and evaluation.

Jocelyn van den Bergen supplied technical support.

Catherine Henry managed the cytogenetic analysis.

Mathilde Domin-Bernhard was involved in patient care and evaluation.

Laurence Cornevin supplied technical support.

Nathalie Dejucq-Rainsford was involved in the functional studies.

Marc-Antoine Belaud-Rotureau participated in project supervision.

Sylvie Odent was involved in patient care and evaluation.

Katie L Ayers conceived and designed the study, and analyzed and interpreted the data.

Célia Ravel was involved in patient care and evaluation.

Elena J Tucker conceived and designed the study, acquired the data, analyzed and interpreted the data, wrote the manuscript, and critically reviewed the manuscript.

Andrew $\mathrm{H}$ Sinclair conceived and designed the study, participated in the project supervision, and critically reviewed the manuscript. 
All authors read and approved the final manuscript.

\section{Conflict of interest}

The authors declare no conflicts of interest.

\section{Funding}

This work was supported by CHU Rennes and Rennes 1 University, Faculty of Medicine in France, a Peter Doherty Early Career Fellowship (1054432; to E.J.T.), a National Health and Medical Research Council program grant (1074258; to A.H.S.), a fellowship (1062854; to A.H.S.) from the Australian National Health and Medical Research Council, the Sigrid Jusélius Foundation (JJP), and the Victorian Government's Operational Infrastructure Support Program. WAS was supported by an Australian Government Research Training Program Stipend scholarship.

\section{Ethical approval}

All procedures were in accordance with the ethical standards of the Ethics Committee of Rennes University Hospital and the French law (favourable opinion from the CCTIRS Comité Consultatif sur le Traitement de l'Information en matière de Recherche dans le domaine de la Santé for the study).

\section{Provenance and peer review}

This article has undergone peer review.

\section{Research data (data sharing and collaboration)}

There are no linked research data sets for this paper. Data will be made available on request.

\section{Acknowledgement}

We would like to thank all the patients and families for taking part in our research.

\section{References}


[1] Forabosco A, Sforza C. Establishment of ovarian reserve: a quantitative morphometric study of the developing human ovary. Fertil Steril 2007;88:675-83.

https://doi.org/10.1016/j.fertnstert.2006.11.191.

[2] Mamsen LS, Lutterodt MC, Andersen EW, Byskov AG, Andersen CY. Germ cell numbers in human embryonic and fetal gonads during the first two trimesters of pregnancy: analysis of six published studies. Hum Reprod Oxf Engl 2011;26:2140-5. https://doi.org/10.1093/humrep/der149.

[3] Gunn HM, Tsai M-C, McRae A, Steinbeck KS. Menstrual Patterns in the First Gynecological Year: A Systematic Review. J Pediatr Adolesc Gynecol 2018;31:557-565.e6. https://doi.org/10.1016/j.jpag.2018.07.009.

[4] Pastore LM, Christianson MS, Stelling J, Kearns WG, Segars JH. Reproductive ovarian testing and the alphabet soup of diagnoses: DOR, POI, POF, POR, and FOR. J Assist Reprod Genet 2018;35:1723. https://doi.org/10.1007/s10815-017-1058-4.

[5] Faubion SS, Kuhle CL, Shuster LT, Rocca WA. Long-term health consequences of premature or early menopause and considerations for management. Climacteric J Int Menopause Soc 2015;18:48391. https://doi.org/10.3109/13697137.2015.1020484.

[6] Tucker EJ, Grover SR, Bachelot A, Touraine P, Sinclair AH. Premature Ovarian Insufficiency: New Perspectives on Genetic Cause and Phenotypic Spectrum. Endocr Rev 2016;37:609-35. https://doi.org/10.1210/er.2016-1047.

[7] Torgerson DJ, Thomas RE, Reid DM. Mothers and daughters menopausal ages: is there a link? Eur J Obstet Gynecol Reprod Biol 1997;74:63-6.

[8] Vegetti W, Grazia Tibiletti M, Testa G, de Lauretis Yankowski null, Alagna F, Castoldi E, et al. Inheritance in idiopathic premature ovarian failure: analysis of 71 cases. Hum Reprod Oxf Engl 1998;13:1796-800.

[9] PashaiasI M, Ebrahimi M, Ebrahimie E. Identification of the key regulating genes of diminished ovarian reserve (DOR) by network and gene ontology analysis. Mol Biol Rep 2016;43:923-37. https://doi.org/10.1007/s11033-016-4025-8.

[10] Jaillard S, Sreenivasan R, Beaumont M, Robevska G, Dubourg C, Knarston IM, et al. Analysis of NR5A1 in 142 patients with premature ovarian insufficiency, diminished ovarian reserve, or unexplained infertility. Maturitas 2020;131:78-86. https://doi.org/10.1016/j.maturitas.2019.10.011.

[11] Sadedin SP, Dashnow H, James PA, Bahlo M, Bauer DC, Lonie A, et al. Cpipe: a shared variant detection pipeline designed for diagnostic settings. Genome Med 2015;7:68. https://doi.org/10.1186/s13073-015-0191-x.

[12] Quang D, Chen Y, Xie X. DANN: a deep learning approach for annotating the pathogenicity of genetic variants. Bioinforma Oxf Engl 2015;31:761-3. https://doi.org/10.1093/bioinformatics/btu703.

[13] Richards S, Aziz N, Bale S, Bick D, Das S, Gastier-Foster J, et al. Standards and guidelines for the interpretation of sequence variants: a joint consensus recommendation of the American College of Medical Genetics and Genomics and the Association for Molecular Pathology. Genet Med Off J Am Coll Med Genet 2015;17:405-24. https://doi.org/10.1038/gim.2015.30.

[14] Venselaar H, Te Beek TAH, Kuipers RKP, Hekkelman ML, Vriend G. Protein structure analysis of mutations causing inheritable diseases. An e-Science approach with life scientist friendly interfaces. BMC Bioinformatics 2010;11:548. https://doi.org/10.1186/1471-2105-11-548.

[15] Mottershead DG, Sugimura S, Al-Musawi SL, Li J-J, Richani D, White MA, et al. Cumulin, an Oocytesecreted Heterodimer of the Transforming Growth Factor- $\beta$ Family, Is a Potent Activator of Granulosa Cells and Improves Oocyte Quality. J Biol Chem 2015;290:24007-20. https://doi.org/10.1074/jbc.M115.671487. 
[16] Rytinki MM, Palvimo JJ. SUMOylation modulates the transcription repressor function of RIP140. J Biol Chem 2008;283:11586-95. https://doi.org/10.1074/jbc.M709359200.

[17] Patiño LC, Walton KL, Mueller TD, Johnson KE, Stocker W, Richani D, et al. BMP15 Mutations Associated With Primary Ovarian Insufficiency Reduce Expression, Activity, or Synergy With GDF9. J Clin Endocrinol Metab 2017;102:1009-19. https://doi.org/10.1210/jc.2016-3503.

[18] Gilchrist RB, Ritter L, Cranfield M, Jeffery LA, Amato F, Scott SJ, et al. Immunoneutralization of growth differentiation factor 9 reveals it partially accounts for mouse oocyte mitogenic activity. Biol Reprod 2004;71:732-9. https://doi.org/10.1095/biolreprod.104.028852.

[19] Peng J, Li Q, Wigglesworth K, Rangarajan A, Kattamuri C, Peterson RT, et al. Growth differentiation factor 9:bone morphogenetic protein 15 heterodimers are potent regulators of ovarian functions. Proc Natl Acad Sci U S A 2013;110:E776-785. https://doi.org/10.1073/pnas.1218020110.

[20] França MM, Funari MFA, Nishi MY, Narcizo AM, Domenice S, Costa EMF, et al. Identification of the first homozygous 1-bp deletion in GDF9 gene leading to primary ovarian insufficiency by using targeted massively parallel sequencing. Clin Genet 2018;93:408-11. https://doi.org/10.1111/cge.13156.

[21] Fouquet B, Pawlikowska P, Caburet S, Guigon C, Mäkinen M, Tanner L, et al. A homozygous FANCM mutation underlies a familial case of non-syndromic primary ovarian insufficiency. ELife 2017;6. https://doi.org/10.7554/eLife.30490.

[22] White R, Leonardsson G, Rosewell I, Ann Jacobs M, Milligan S, Parker M. The nuclear receptor corepressor nrip1 (RIP140) is essential for female fertility. Nat Med 2000;6:1368-74. https://doi.org/10.1038/82183.

[23] Nautiyal J. Transcriptional coregulator RIP140: an essential regulator of physiology. J Mol Endocrinol 2017;58:R147-58. https://doi.org/10.1530/JME-16-0156.

[24] Mihalas BP, Western PS, Loveland KL, McLaughlin EA, Holt JE. Changing expression and subcellular distribution of karyopherins during murine oogenesis. Reprod Camb Engl 2015;150:485-96. https://doi.org/10.1530/REP-14-0585.

[25] Onuma A, Fujioka YA, Fujii W, Sugiura K, Naito K. Effects of exportin 1 on nuclear transport and meiotic resumption in porcine full-grown and growing oocytes. Biol Reprod 2018;98:501-9. https://doi.org/10.1093/biolre/iox168.

[26] Tomizuka K, Horikoshi K, Kitada R, Sugawara Y, Iba Y, Kojima A, et al. R-spondin1 plays an essential role in ovarian development through positively regulating Wnt-4 signaling. Hum Mol Genet 2008;17:1278-91. https://doi.org/10.1093/hmg/ddn036.

[27] Gupta T, Marlow FL, Ferriola D, Mackiewicz K, Dapprich J, Monos D, et al. Microtubule actin crosslinking factor 1 regulates the Balbiani body and animal-vegetal polarity of the zebrafish oocyte. PLoS Genet 2010;6:e1001073. https://doi.org/10.1371/journal.pgen.1001073.

[28] Lee J, Lee S, Chen C, Shim H, Kim-Ha J. shot regulates the microtubule reorganization required for localization of axis-determining mRNAs during oogenesis. FEBS Lett 2016;590:431-44. https://doi.org/10.1002/1873-3468.12086.

[29] Belli M, Shimasaki S. Molecular Aspects and Clinical Relevance of GDF9 and BMP15 in Ovarian Function. Vitam Horm 2018;107:317-48. https://doi.org/10.1016/bs.vh.2017.12.003.

[30] Simpson CM, Robertson DM, Al-Musawi SL, Heath DA, McNatty KP, Ritter LJ, et al. Aberrant GDF9 expression and activation are associated with common human ovarian disorders. J Clin Endocrinol Metab 2014;99:E615-624. https://doi.org/10.1210/jc.2013-3949.

[31] Wang T-T, Ke Z-H, Song Y, Chen L-T, Chen X-J, Feng C, et al. Identification of a mutation in GDF9 as a novel cause of diminished ovarian reserve in young women. Hum Reprod 2013;28:2473-81. https://doi.org/10.1093/humrep/det291.

[32] Hanrahan JP, Gregan SM, Mulsant P, Mullen M, Davis GH, Powell R, et al. Mutations in the genes for oocyte-derived growth factors GDF9 and BMP15 are associated with both increased ovulation 
rate and sterility in Cambridge and Belclare sheep (Ovis aries). Biol Reprod 2004;70:900-9. https://doi.org/10.1095/biolreprod.103.023093.

[33] Jolly A, Bayram Y, Turan S, Aycan Z, Tos T, Abali ZY, et al. Exome Sequencing of a Primary Ovarian Insufficiency Cohort Reveals Common Molecular Etiologies for a Spectrum of Disease. J Clin Endocrinol Metab 2019;104:3049-67. https://doi.org/10.1210/jc.2019-00248.

[34] Basbous J, Constantinou A. A tumor suppressive DNA translocase named FANCM. Crit Rev Biochem Mol Biol 2019;54:27-40. https://doi.org/10.1080/10409238.2019.1568963.

[35] Kasak L, Punab M, Nagirnaja L, Grigorova M, Minajeva A, Lopes AM, et al. Bi-allelic Recessive Lossof-Function Variants in FANCM Cause Non-obstructive Azoospermia. Am J Hum Genet 2018;103:200-12. https://doi.org/10.1016/j.ajhg.2018.07.005.

[36] Yin H, Ma H, Hussain S, Zhang H, Xie X, Jiang L, et al. A homozygous FANCM frameshift pathogenic variant causes male infertility. Genet Med Off J Am Coll Med Genet 2019;21:62-70. https://doi.org/10.1038/s41436-018-0015-7.

[37] Schubert S, van Luttikhuizen JL, Auber B, Schmidt G, Hofmann W, Penkert J, et al. The identification of pathogenic variants in BRCA1/2 negative, high risk, hereditary breast and/or ovarian cancer patients: High frequency of FANCM pathogenic variants. Int J Cancer 2019;144:2683-94. https://doi.org/10.1002/ijc.31992.

[38] Flageole C, Toufaily C, Bernard DJ, Ates S, Blais V, Chénier S, et al. Successful in vitro maturation of oocytes in a woman with gonadotropin-resistant ovary syndrome associated with a novel combination of FSH receptor gene variants: a case report. J Assist Reprod Genet 2019;36:425-32. https://doi.org/10.1007/s10815-018-1394-z.

[39] He W-B, Du J, Yang X-W, Li W, Tang W-L, Dai C, et al. Novel inactivating mutations in the FSH receptor cause premature ovarian insufficiency with resistant ovary syndrome. Reprod Biomed Online 2019;38:397-406. https://doi.org/10.1016/j.rbmo.2018.11.011.

[40] Touraine P, Beau I, Gougeon A, Meduri G, Desroches A, Pichard C, et al. New natural inactivating mutations of the follicle-stimulating hormone receptor: correlations between receptor function and phenotype. Mol Endocrinol Baltim Md 1999;13:1844-54. https://doi.org/10.1210/mend.13.11.0370.

[41] Beau I, Groyer-Picard M-T, Desroches A, Condamine E, Leprince J, Tomé J-P, et al. The basolateral sorting signals of the thyrotropin and luteinizing hormone receptors: an unusual family of signals sharing an unusual distal intracellular localization, but unrelated in their structures. Mol Endocrinol Baltim Md 2004;18:733-46. https://doi.org/10.1210/me.2003-0130.

[42] Cavaillès V, Dauvois S, L'Horset F, Lopez G, Hoare S, Kushner PJ, et al. Nuclear factor RIP140 modulates transcriptional activation by the estrogen receptor. EMBO J 1995;14:3741-51.

[43] Lee CH, Chinpaisal C, Wei LN. Cloning and characterization of mouse RIP140, a corepressor for nuclear orphan receptor TR2. Mol Cell Biol 1998;18:6745-55. https://doi.org/10.1128/mcb.18.11.6745.

[44] Subramaniam N, Treuter E, Okret S. Receptor interacting protein RIP140 inhibits both positive and negative gene regulation by glucocorticoids. J Biol Chem 1999;274:18121-7. https://doi.org/10.1074/jbc.274.25.18121.

[45] Treuter E, Albrektsen T, Johansson L, Leers J, Gustafsson JA. A regulatory role for RIP140 in nuclear receptor activation. Mol Endocrinol Baltim Md 1998;12:864-81. https://doi.org/10.1210/mend.12.6.0123.

[46] Lee $\mathrm{CH}$, Wei LN. Characterization of receptor-interacting protein 140 in retinoid receptor activities. J Biol Chem 1999;274:31320-6. https://doi.org/10.1074/jbc.274.44.31320.

[47] Miyauchi H, Ohta H, Nagaoka S, Nakaki F, Sasaki K, Hayashi K, et al. Bone morphogenetic protein and retinoic acid synergistically specify female germ-cell fate in mice. EMBO J 2017;36:3100-19. https://doi.org/10.15252/embj.201796875. 
[48] Vivante A, Mann N, Yonath H, Weiss A-C, Getwan M, Kaminski MM, et al. A Dominant Mutation in Nuclear Receptor Interacting Protein 1 Causes Urinary Tract Malformations via Dysregulation of Retinoic Acid Signaling. J Am Soc Nephrol JASN 2017;28:2364-76. https://doi.org/10.1681/ASN.2016060694.

[49] Fung HYJ, Chook YM. Atomic basis of CRM1-cargo recognition, release and inhibition. Semin Cancer Biol 2014;27:52-61. https://doi.org/10.1016/j.semcancer.2014.03.002.

[50] Hu L, Su P, Li R, Yin C, Zhang Y, Shang P, et al. Isoforms, structures, and functions of versatile spectraplakin MACF1. BMB Rep 2016;49:37-44. https://doi.org/10.5483/BMBRep.2016.49.1.185.

[51] Chen H-J, Lin C-M, Lin C-S, Perez-Olle R, Leung CL, Liem RKH. The role of microtubule actin crosslinking factor 1 (MACF1) in the Wnt signaling pathway. Genes Dev 2006;20:1933-45. https://doi.org/10.1101/gad.1411206.

[52] Iwase S, Sato R, De Bock P-J, Gevaert K, Fujiki S, Tawada T, et al. Activation of ADF/cofilin by phosphorylation-regulated Slingshot phosphatase is required for the meiotic spindle assembly in Xenopus laevis oocytes. Mol Biol Cell 2013;24:1933-46. https://doi.org/10.1091/mbc.E12-120851.

[53] Tucker EJ, Jaillard S, Grover SR, den Bergen J, Robevska G, Bell KM, et al. TP63-truncating variants cause isolated premature ovarian insufficiency. Hum Mutat 2019. https://doi.org/10.1002/humu.23744.

[54] Costas J, Suárez-Rama JJ, Carrera N, Paz E, Páramo M, Agra S, et al. Role of DISC1 interacting proteins in schizophrenia risk from genome-wide analysis of missense SNPs. Ann Hum Genet 2013;77:504-12. https://doi.org/10.1111/ahg.12037.

[55] Wang X, Li N, Xiong N, You Q, Li J, Yu J, et al. Genetic Variants of Microtubule Actin Cross-linking Factor 1 (MACF1) Confer Risk for Parkinson's Disease. Mol Neurobiol 2017;54:2878-88. https://doi.org/10.1007/s12035-016-9861-y.

[56] Miao Z, Ali A, Hu L, Zhao F, Yin C, Chen C, et al. Microtubule actin cross-linking factor 1, a novel potential target in cancer. Cancer Sci 2017;108:1953-8. https://doi.org/10.1111/cas.13344.

[57] Jørgensen LH, Mosbech M-B, Færgeman NJ, Graakjaer J, Jacobsen SV, Schrøder HD. Duplication in the microtubule-actin cross-linking factor 1 gene causes a novel neuromuscular condition. Sci Rep 2014;4:5180. https://doi.org/10.1038/srep05180.

[58] Dobyns WB, Aldinger KA, Ishak GE, Mirzaa GM, Timms AE, Grout ME, et al. MACF1 Mutations Encoding Highly Conserved Zinc-Binding Residues of the GAR Domain Cause Defects in Neuronal Migration and Axon Guidance. Am J Hum Genet 2018;103:1009-21. https://doi.org/10.1016/j.ajhg.2018.10.019.

[59] Robevska G, van den Bergen JA, Ohnesorg T, Eggers S, Hanna C, Hersmus R, et al. Functional characterization of novel NR5A1 variants reveals multiple complex roles in disorders of sex development. Hum Mutat 2018;39:124-39. https://doi.org/10.1002/humu.23354.

[60] Patiño LC, Beau I, Carlosama C, Buitrago JC, González R, Suárez CF, et al. New mutations in nonsyndromic primary ovarian insufficiency patients identified via whole-exome sequencing. Hum Reprod Oxf Engl 2017;32:1512-20. https://doi.org/10.1093/humrep/dex089.

[61] Delcour C, Amazit L, Patino LC, Magnin F, Fagart J, Delemer B, et al. ATG7 and ATG9A loss-offunction variants trigger autophagy impairment and ovarian failure. Genet Med Off J Am Coll Med Genet 2019;21:930-8. https://doi.org/10.1038/s41436-018-0287-y.

[62] Wang B, Li L, Zhu Y, Zhang W, Wang X, Chen B, et al. Sequence variants of KHDRBS1 as high penetrance susceptibility risks for primary ovarian insufficiency by mis-regulating mRNA alternative splicing. Hum Reprod Oxf Engl 2017;32:2138-46.

https://doi.org/10.1093/humrep/dex263. 


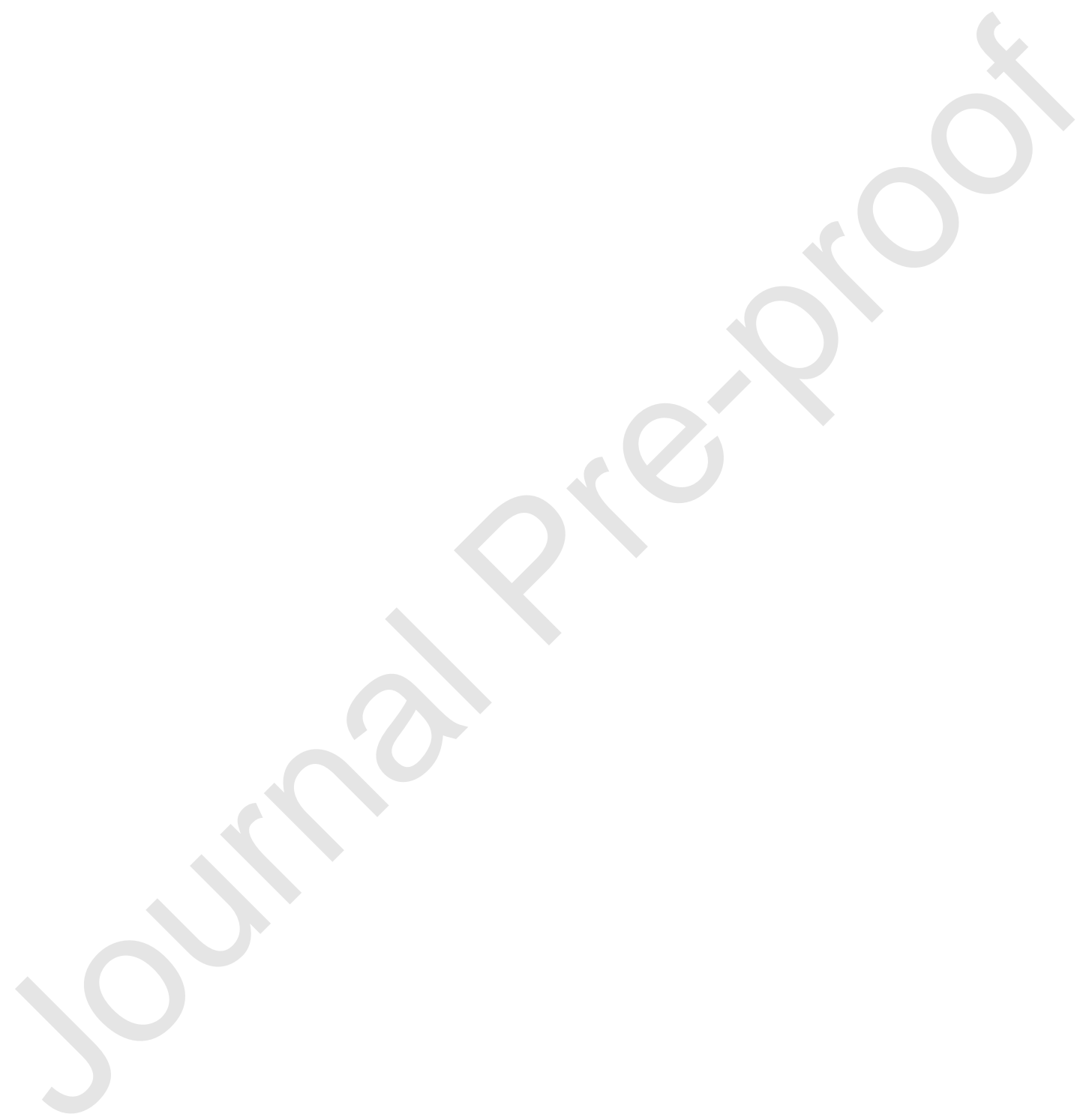




\section{Legend to Figures and Tables}

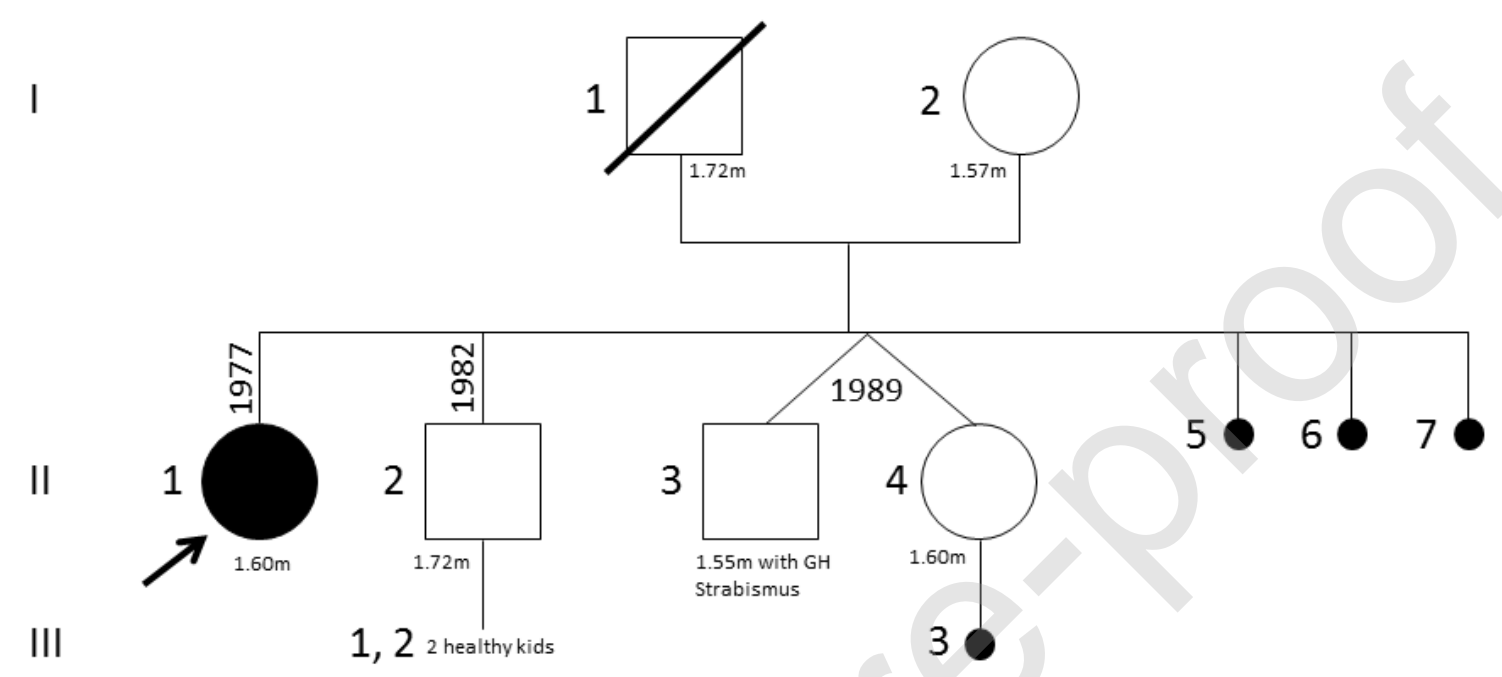

Figure 1a 


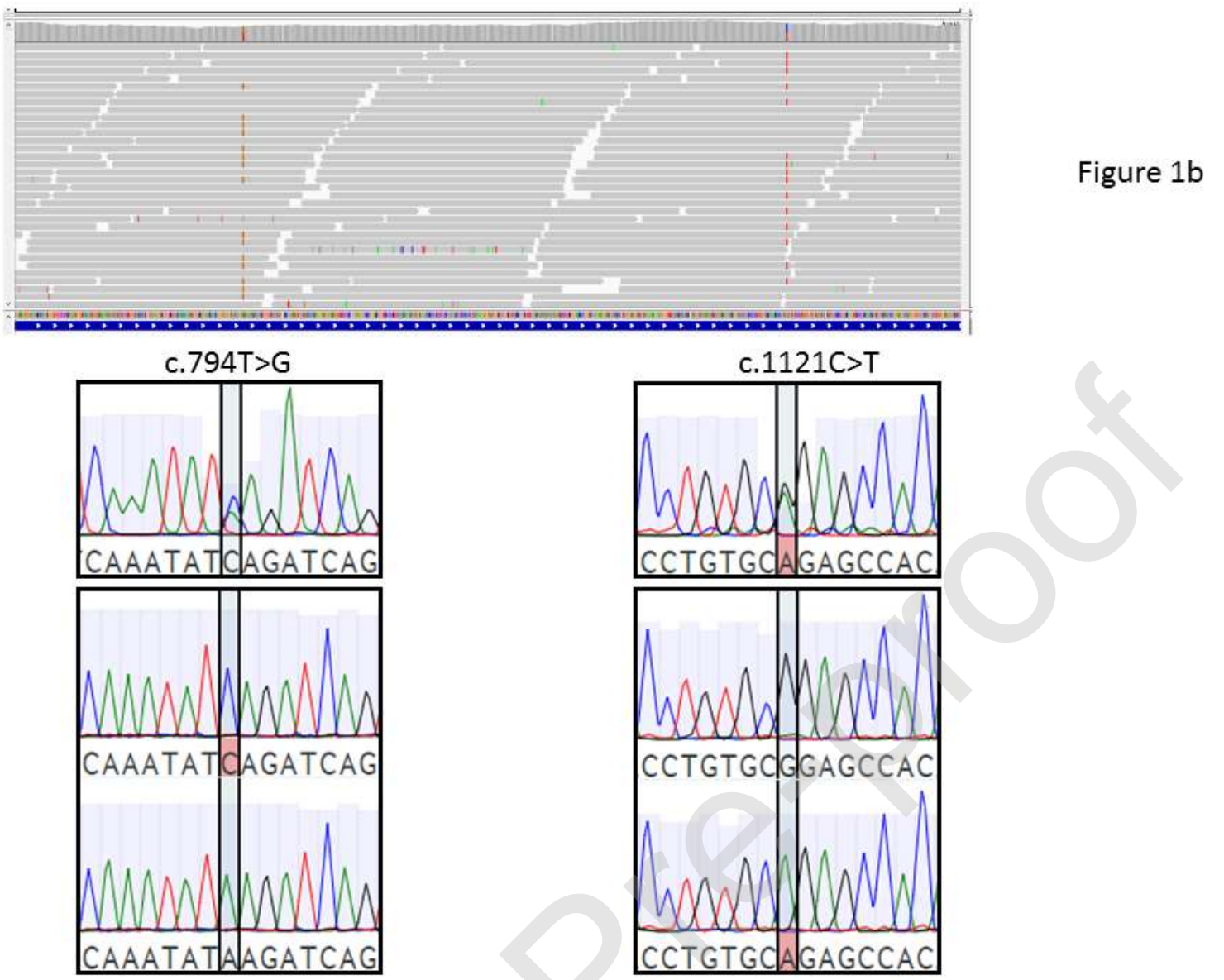




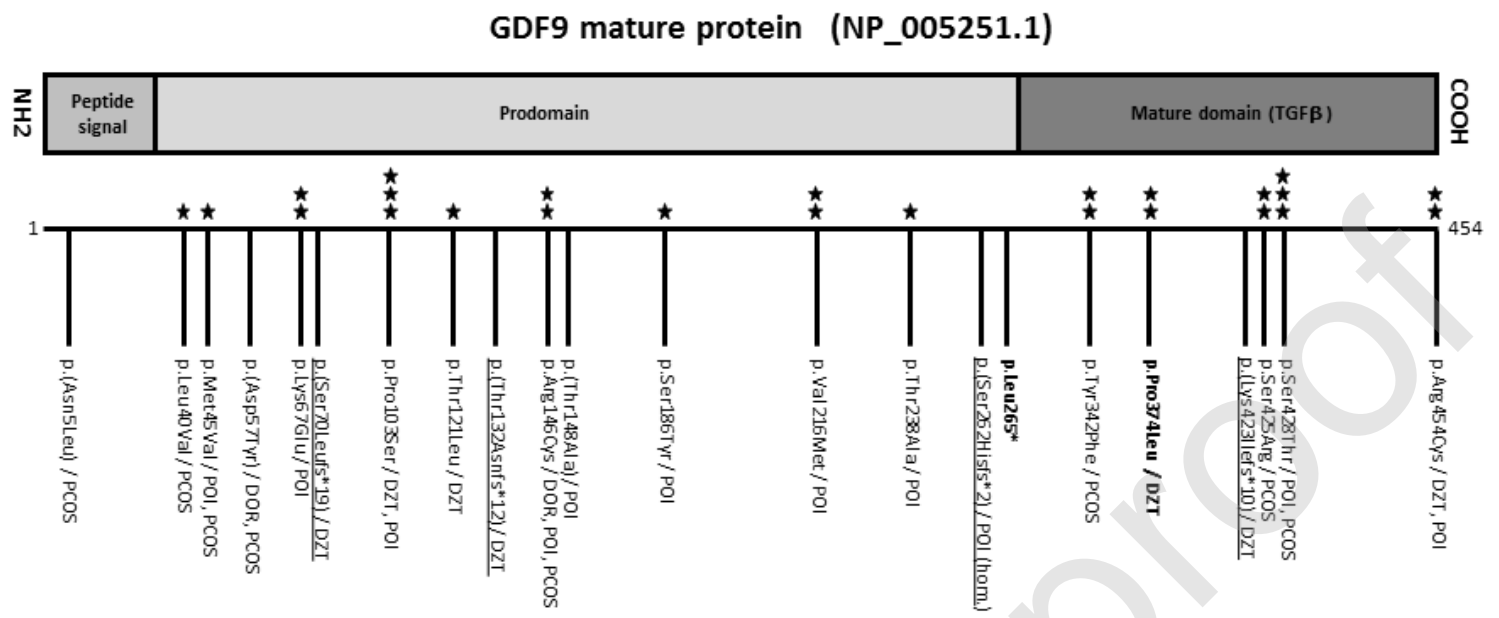

No functional studies

$\star$ Weak reduction of expression

$\star \star$ Strong reduction of expression

Figure 1c

$\star \star \star$ Loss of expression

Nonsense variants 


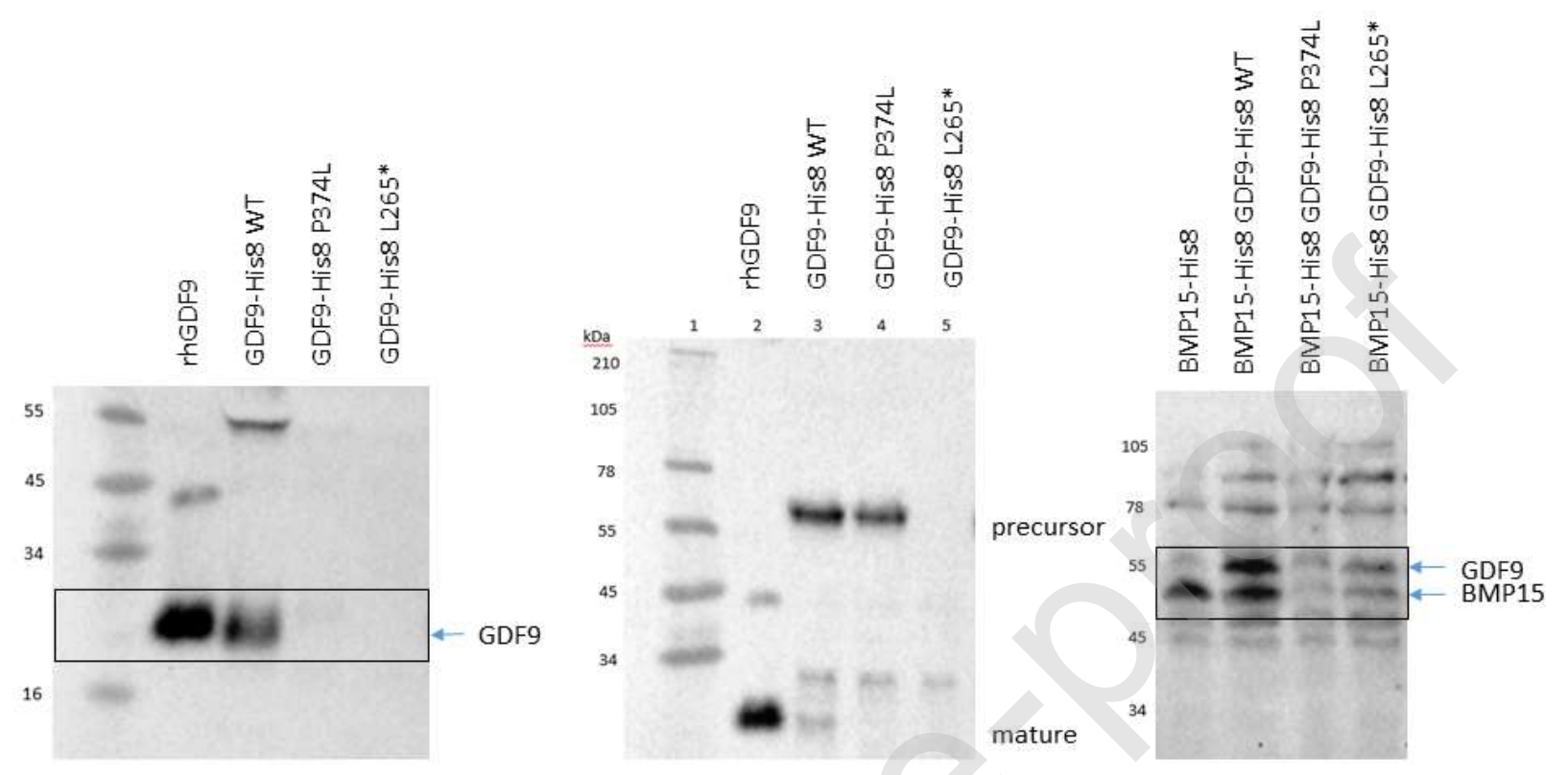

Figure 1d

Figure 1. Likely pathogenic variants in GDF9.

1a: Familial pedigree of Patient 2

The proband is indicated by an arrow. Small solid black circles represent voluntary termination of pregnancy (II5, II6, and II7) or miscarriage (III3). Information on height is given for individuals I2, II1, II2, $\| 3$ and $\| 4$. Years of birth are indicated for the sibling $\|1\| 2,, \| 3$, and $\| 4$. GH: growth hormone.

1b: Sequencing results of Patient 2

Top: IGV visualization of the GDF9 variants in Patient 2, showing variants physically close to each other Middle: Sanger sequencing of GDF9 in Patient 2 confirming the presence of heterozygous variants Bottom: Variant phasing, showing phased variants, and confirming compound heterozygosity (presence of one variant per clone, each clone corresponding to one line)

1c: Gene diagram showing variants position with respect to previously reported variants involved in POI (premature ovarian insufficiency), DOR (diminished ovarian reserve), PCOS (polycystic ovarian syndrome), and DZT (dizygotic twin). Reported variants are heterozygous except one homozygous (hom.) NH2: Amino terminal domain, $\mathrm{COOH}$ : Carboxy terminal domain. One star: functional studies 
showing weak reduction of expression, two stars: functional studies showing strong reduction of expression, three stars: functional studies showing loss of expression, underline: non-sense variants, bold: variants observed in our patient.

1d: Western blot of GDF9 in vitro expression

Left: Variants impair protein production/secretion in conditioned media. Detection of WT GDF9 (rhGDF9: recombinant human and GDF9-His8: HIS-tagged GDF9) and poor/absent detection of GDF9P374L and GDF9-L265* (black box), indicating the variants impair the production of GDF9 and/or its secretion into conditioned media.

Middle: Analysis of precursor and mature GDF9 intracellularly. Successful processing of WT HIS-tagged GDF9 (3). Detection of precursor GDF9-P374L without detection of mature protein suggesting impaired processing (4). Absence of detection of precursor and mature GDF9-L265* confirming lack of expression resulting from premature stop codon (5).

Right: Variants impair BMP15-GDF9 interaction intracellularly. Detection of HIS-tagged BMP15 and WT GDF9 indicating they complement each other. Weak detection of HIS-tagged BMP15 and either GDF9P374L or GDF9-L265* (black box), indicating the complementary interaction is not achieved with mutant GDF9. 

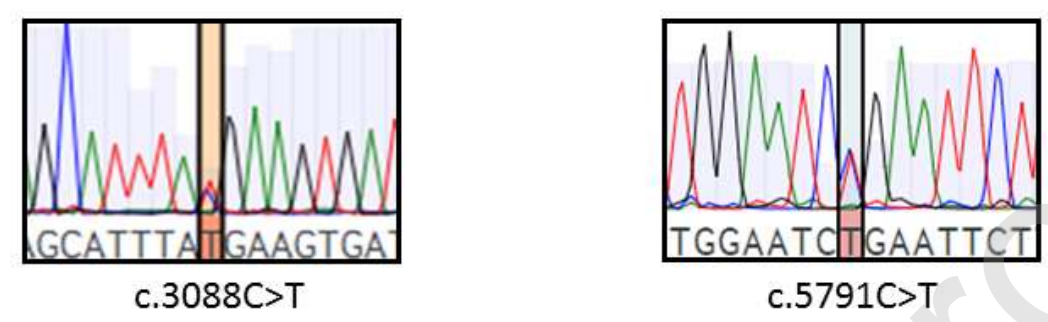

Figure 2a 


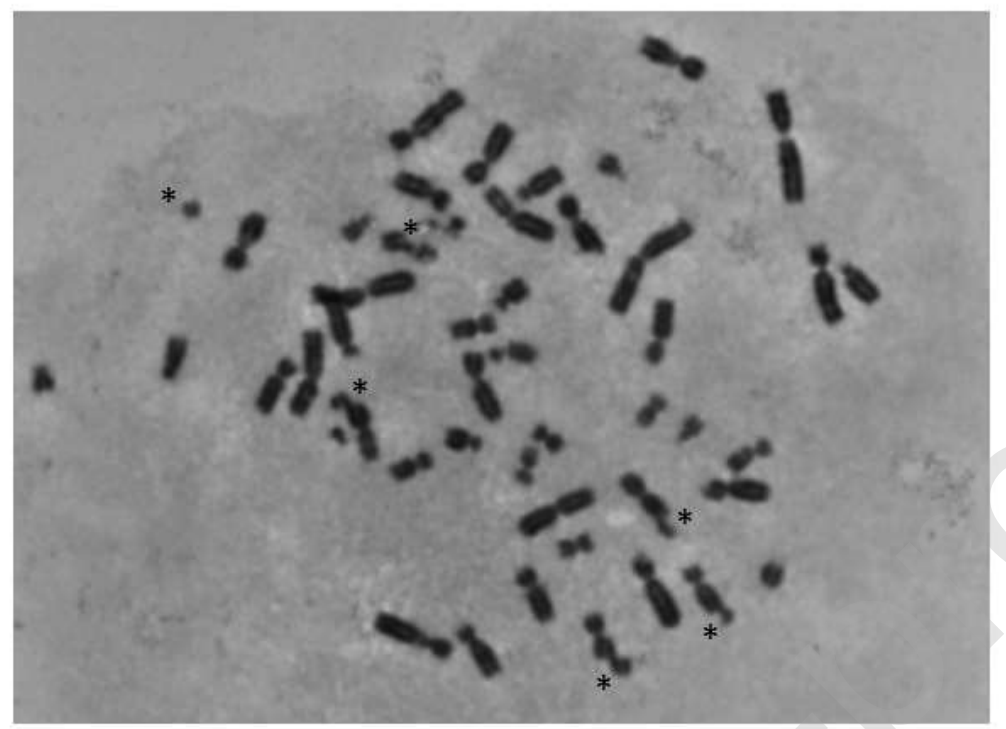

Figure $2 b$

\section{Figure 2. Pathogenic variants in FANCM.}

2a: Sanger sequencing of FANCM in Patient 5 confirming the presence of heterozygous variants

2b: Karyotype with induction of chromosome breakage by using mitomycin C. Breakages are indicated by asterisks. 


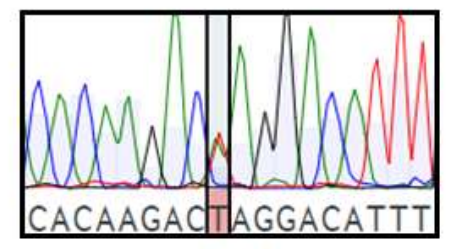

c. $3259 \mathrm{~A}>\mathrm{T}$

Figure 3a 
NRIP1 protein (NP_003480.2)

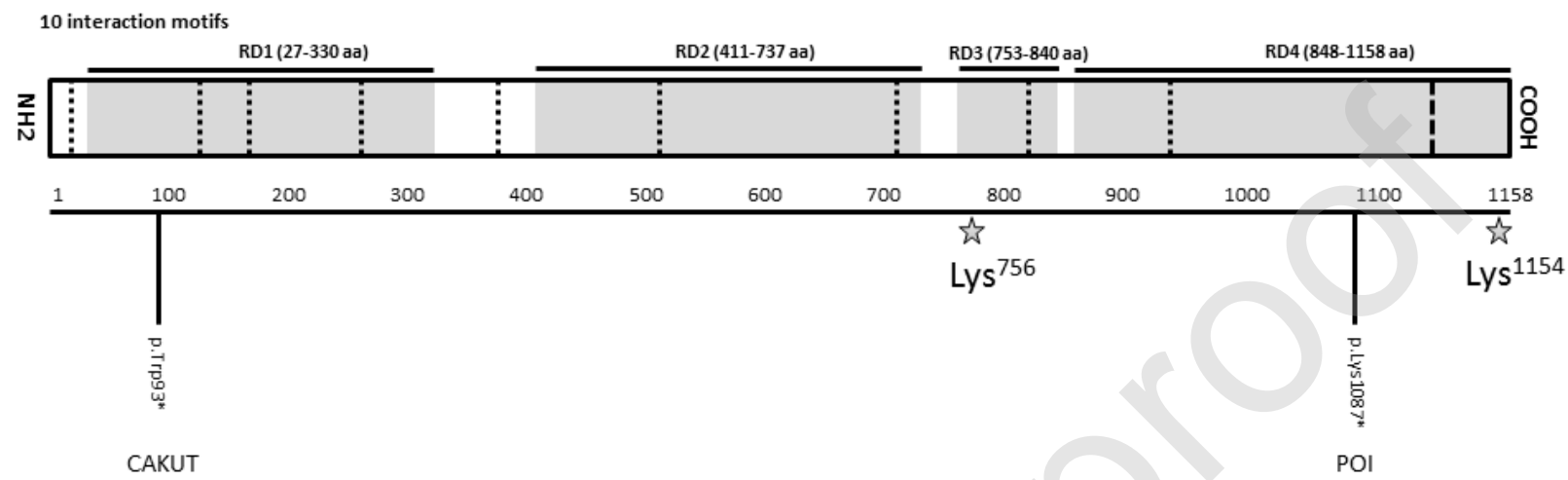

Figure $3 b$ 

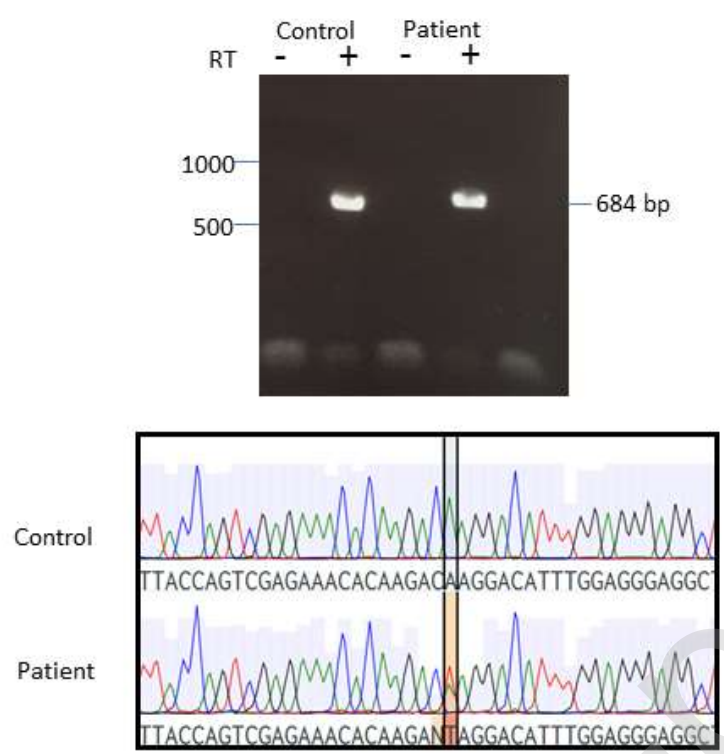

Figure $3 c$ 


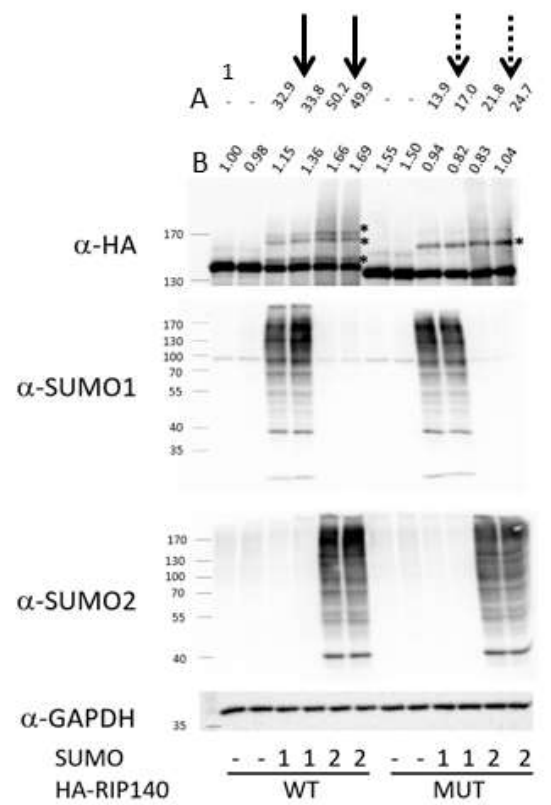

Figure 3d 


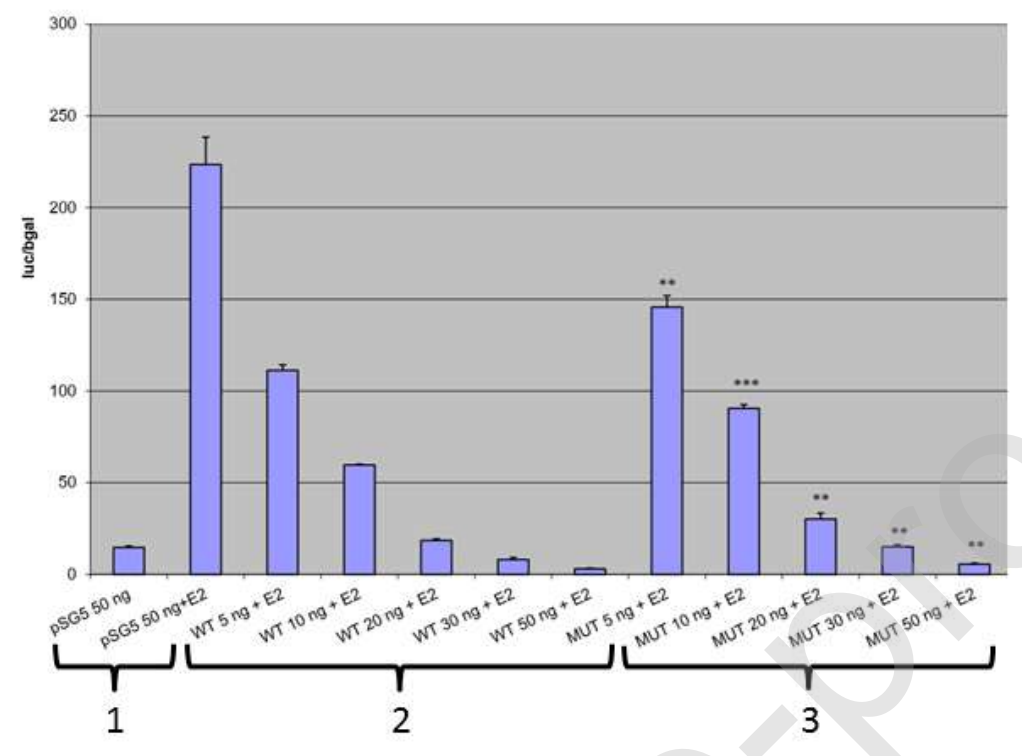

Figure $3 e$

Figure 3. NRIP1 is a candidate gene.

3a: Sanger sequencing of NRIP1 in Patient 9 confirming the presence of heterozygous variant

3b: NRIP1 protein diagram (according to InterPro description https://www.ebi.ac.uk) and variants location observed in human with respect to protein domains. Grey boxes: transcriptional repression domains (RD1-4). Small dot lines: nine interaction motifs LxxLL. Large dot line: interaction motif LxxML. CAKUT: Congenital Anomalies of the Kidney and Urinary Tract. POI: Premature Ovarian Insufficiency. Stars: Small Ubiquitin-like Modifier acceptor lysines.

3c: RT-PCR proving transcript stability. A clear expression of both the mutant and wild-type sequence in patient cDNA is observed on both electrophoresis (top) showing a unique same-sized band as in the control and on sequencing with RT-PCR (bottom). Negative controls without reverse transcriptase (-RT) confirm lack of residual gDNA contributing to the sequencing products.

3d: In vitro evidence of variant impact, Western blot. Line A: percentage of NRIP1 SUMOylated relative to total NRIP1. Line B: total WT and variant NRIP1 expression (unSUMOylated and SUMOylated forms, relative to GAPDH). $\alpha$-HA, $\alpha$-SUMO1, $\alpha$-SUMO2, and $\alpha$-GAPDH: antibodies. $~ 33 \%$ of WT NRIP1 is 
SUMOylated by SUMO1 and $50 \%$ by SUMO2 (black arrows), 16\% of variant NRIP1 is SUMOylated by SUMO1 and $\sim 23 \%$ by SUMO2 (dotted arrows). Asterisks indicate SUMOylated forms of NRIP1. For analysis, total amount of NRIP1 was first determined by measuring the bands close to $130 \mathrm{kDa}$ as well as the larger bands closer to $170 \mathrm{kDa}$ (unSUMOylated + SUMOylated NRIP1). This was expressed relative to GAPDH expression and relative to wild-type unSUMOylated sample (Lane 1).

3e: In vitro evidence of variant impact, ER $\alpha$-dependent luciferase reporter. Variant NRIP1 is less efficient in repressing estradiol (E2)-induced transcription by ER $\alpha$. The addition E2 increases the relative expression from this reporter by 14-fold (from 14 to >200 luc/Bgal) (1). E2-induced ERa-dependent reporter expression is repressed by the addition of WT NRIP1, and the degree of repression increases as the level of NRIP1 protein increases (2). The ability of variant NRIP1 to repress ER $\alpha$-dependent reporter expression in response to E2 is significantly hampered at all expression levels (3). 
Table I: Summary of the clinical and molecular findings for the 10 patients of the study.

\begin{tabular}{|c|c|c|c|c|c|c|c|c|c|c|}
\hline & Patient 1 (POI) & Patient 2 (POI) & Patient 3 (POI) & Patient 4 (POI) & Patient 5 (POI) & Patient 6 (POI) & Patient 7 (POI) & Patient 8 (POI) & $\begin{array}{l}\text { Patient } 9 \\
\text { (POI/DOR) }\end{array}$ & Patient 10 (DOR) \\
\hline Menstruation & $\begin{array}{c}\text { Primary } \\
\text { amenorrhea }\end{array}$ & $\begin{array}{c}\text { Primary } \\
\text { amenorrhea }\end{array}$ & $\begin{array}{c}\text { Primary } \\
\text { amenorrhea }\end{array}$ & $\begin{array}{c}\text { Primary } \\
\text { amenorrhea }\end{array}$ & $\begin{array}{c}\text { Secondary } \\
\text { amenorrhea }\end{array}$ & $\begin{array}{c}\text { Secondary } \\
\text { amenorrhea }\end{array}$ & $\begin{array}{c}\text { Secondary } \\
\text { amenorrhea }\end{array}$ & $\begin{array}{c}\text { Secondary } \\
\text { amenorrhea }\end{array}$ & $\mathrm{N}$ & $\mathrm{N}$ \\
\hline FSH UI/I & 95 & 68.5 & 46.5 & 56.9 & 61 & 31 & 49.8 & 91.5 & 30.1 & 9.3 \\
\hline LH UI/I & 30 & 55 & 24.5 & 39.1 & 52 & NA & 83.4 & 47.4 & 5.9 & 4.3 \\
\hline $\mathrm{E} 2 \mathrm{pg} / \mathrm{ml}$ & 11 & Low & 33 & 24.5 & 25.2 & 15.8 & 152.7 & 9 & $<20$ & 62 \\
\hline $\mathrm{AMH} \mathrm{ng} / \mathrm{ml}$ & $<0.03$ & $<0.4$ & NA & 3.2 & $<0.1$ & 0.4 & 0.3 & $<0.4$ & 0.4 & 0.8 \\
\hline Prolactine $\mathrm{ng} / \mathrm{ml}$ & NA & $6.7(\mathrm{~N})$ & $\mathrm{N}$ & NA & $10.1(\mathrm{~N})$ & NA & NA & $20.9(N)$ & $\begin{array}{c}24.3 \text { (high) } \rightarrow \\
19.4(\mathrm{~N})\end{array}$ & $\begin{array}{c}27 \text { (high) } \rightarrow 19.3 \\
(\mathrm{~N})\end{array}$ \\
\hline US & $\begin{array}{l}\text { Small uterus } \\
\text { and ovaries } \\
\text { without follicles }\end{array}$ & $\begin{array}{c}\text { Endometrial } \\
\text { atrophy } \\
\text { AFC }=0\end{array}$ & $\begin{array}{c}\text { Small uterus } \\
\text { Small right } \\
\text { ovary with small } \\
\text { follicles } \\
\text { Atrophic left } \\
\text { ovary (not seen) }\end{array}$ & $A F C=6$ & $\begin{array}{l}\text { Normal uterus, } \\
\text { small ovaries } \\
\text { without follicles }\end{array}$ & $\begin{array}{l}\text { Small ovaries } \\
\text { without follicles }\end{array}$ & NA & NA & $\mathrm{AFC}=4$ & $\mathrm{AFC}=10$ \\
\hline Age at diagnosis & 17 & 18 & 15 & 20 & 24 & 37 & 29 & 26 & 29 & 33 \\
\hline $\begin{array}{l}\text { Age of maternal } \\
\text { menopause }\end{array}$ & $\begin{array}{c}\text { Reported } \\
\text { normal }\end{array}$ & $\begin{array}{c}\text { Reported } \\
\text { normal }\end{array}$ & 50 & NA & 55 & 55 & 55 & NA & NA & 40 \\
\hline Karyotype & $46, X X$ & $46, X X$ & $46, X X$ & $46, X X$ & $46, X X$ & $46, X X$ & $46, X X$ & $46, X X$ & $46, X X$ & $46, X X$ \\
\hline FMR1 screening & $\mathrm{N}$ & $\mathrm{N}$ & $\mathrm{N}$ & $\mathrm{N}$ & $\mathrm{N}$ & $\mathrm{N}$ & $\mathrm{N}$ & $\mathrm{N}$ & $\mathrm{N}$ & $\mathrm{N}$ \\
\hline Microarray & $\mathrm{N}$ & $\mathrm{N}$ & $\mathrm{N}$ & $\mathrm{N}$ & $\mathrm{N}$ & $\mathrm{N}$ & $\mathrm{N}$ & $\mathrm{N}$ & $\mathrm{N}$ & $\mathrm{N}$ \\
\hline Auto-Ab & NA & NA & TPO-, TG- & NA & $\begin{array}{c}\text { TPO- } \\
210 \mathrm{OH}- \\
\text { Ovarian-Ab- }\end{array}$ & $\begin{array}{l}\text { TPO-, TG- } \\
210 \mathrm{OH}-\end{array}$ & $\begin{array}{l}\text { ACA- } \\
210 \mathrm{OH}-\end{array}$ & $\begin{array}{c}\text { TPO-, TG- } \\
210 H-\end{array}$ & $\begin{array}{c}\text { TPO- } \\
\text { Ovarian-Ab- }\end{array}$ & $\begin{array}{c}\text { TPO-, TG- } \\
\text { ACA- }\end{array}$ \\
\hline Medical history & $\begin{array}{c}\text { No spontaneous } \\
\text { puberty } \\
\text { Primary } \\
\text { infertility } \\
\text { Hashimoto } \\
\text { thyroiditis }\end{array}$ & OD program & OD program & $\begin{array}{c}\text { Primary } \\
\text { infertility } \\
\text { OD program }\end{array}$ & $\begin{array}{c}\text { Menarche } 11 \text { yo } \\
\text { Primary } \\
\text { infertility } \\
\text { OD program }\end{array}$ & $\begin{array}{c}\text { Menarche } 12 \text { yo } \\
1 \text { child } \\
\text { (spontaneous } \\
\text { pregnancy) } \\
\text { OD program }\end{array}$ & $\begin{array}{c}\text { Menarche } 11 \text { yo } \\
\text { Primary } \\
\text { infertility } \\
\text { OD program }\end{array}$ & $\begin{array}{l}\text { Menarche } 12 \text { yo } \\
\text { Pierre Robin } \\
\text { sequence } \\
\text { Secondary } \\
\text { hearing loss } \\
\text { OD program }\end{array}$ & $\begin{array}{c}\text { Menarche } 13 \text { yo } \\
\text { Primary } \\
\text { infertility } \\
\text { Cervical hernia } \\
\text { Strabismus } \\
\text { OD program }\end{array}$ & $\begin{array}{c}\text { Menarche } 12 \text { yo } \\
1 \text { child, } 2 \\
\text { miscarriages, } 1 \\
\text { VTP (other } \\
\text { partner) }\end{array}$ \\
\hline Familial history & / & $\begin{array}{c}\text { Three } \\
\text { miscarriages in } \\
\text { the mother, one } \\
\text { healthy brother, } \\
\text { twins sibling }\end{array}$ & $\begin{array}{c}\text { Consanguineous } \\
\text { parents } \\
\text { One infertile } \\
\text { brother (non- } \\
\text { obstructive }\end{array}$ & / & $\begin{array}{l}\text { One sister with } \\
\text { POI at } 28 \text { yo } \\
\text { No history of } \\
\text { breast cancer }\end{array}$ & / & / & / & / & $\begin{array}{l}\text { One infertile } \\
\text { paternal aunt }\end{array}$ \\
\hline
\end{tabular}




\begin{tabular}{|c|c|c|c|c|c|c|c|c|c|c|}
\hline & & $\begin{array}{l}\text { (sister with one } \\
\text { miscarriage, } \\
\text { brother with } \\
\text { small size and } \\
\text { strabismus) }\end{array}$ & azoospermia) & & & & & & & \\
\hline $\begin{array}{l}{ }^{\mathrm{a}} \text { Genes of } \\
\text { interest }\end{array}$ & $\begin{array}{l}\text { TAF4B, IRS4, } \\
\text { ZNF462, } \\
\text { ZNF462, } \\
\text { SOHLH1 }\end{array}$ & GDF9 & STAG3 & $\begin{array}{l}\text { FSHR, ERCC6- } \\
\text { PGBD3, NUP50 }\end{array}$ & $\begin{array}{l}\text { AMH, MCM } 8 \\
\text { FANCM }\end{array}$ & $\begin{array}{l}\text { COL4AG, POLG, } \\
\text { MACF1 }\end{array}$ & $\begin{array}{l}\text { ERCC6-PGBD3, } \\
\text { BMPR1B, FSHR }\end{array}$ & $\begin{array}{l}\text { DCAF1 (VPRBP), } \\
\text { NUP107, } \\
\text { PARP1, PNPLA7 }\end{array}$ & $\begin{array}{l}\text { NRIP1, RSPO1, } \\
\text { XPO1 }\end{array}$ & $\begin{array}{l}\text { SGOL2, PRLR, } \\
\text { NUP107, } \\
\text { ADAMTS1 }\end{array}$ \\
\hline
\end{tabular}

Table I

a Refer to Supplementary File 2 for variant details. Bold indicates diagnostic variants and/or variants for which the is substantial support for gene involvement in POI pathogenesis.

FSH: follicle stimulating hormone, LH: luteinizing hormone, E2: estradiol, AMH: anti-Müllerian hormone, US: ultrasound, AFC: antral follicular count, N: normal, NA: non-available, Ab: antibody, TPO:

anti-thyroperoxydase, TG: anti-thyroglobuline, yo: years old, OD: oocyte donation, VTP: voluntary termination of pregnancy, POI: premature ovarian insufficiency, DOR: diminished ovarian reserve

\section{Supplementary File 1: Detailed method for phasing by cloning}

Supplementary File 2: Summary of variants of interest

\section{Supplementary File 3: GDF9 ELISA assay}

Supplementary File 4: Variants of uncertain significance of FSHR

Supplementary File 5: Discussion of variants of interest in unsolved patients 